ISSN: 0213-2060

DOI: https://doi.org/10.14201/shhme20183613156

\title{
CASTILLOS, CASTROS Y FORTALEZAS DURANTE LA EXPANSIÓN DEL REINO DE LEÓN. PODER Y FUNCIONES EN LA MONTAÑA LEONESA Y EL INTERFLUVIO TÁVORA-CÔA $(\text { SIGLOS X-XI })^{1}$
}

\author{
Castles, Castra and Fortresses during the Kingdom of Leon Expansion. Power \\ and Roles within the Mountains of Leon and the Tavora-Côa Watershed \\ (10 and $11^{\text {th }}$ Centuries)
}

\author{
Daniel JUSTO SÁNCHEZ \\ Depto. de Historia Medieval, Moderna y Contemporánea. Facultad de Geografía e Historia. Universidad de Sala- \\ manca. C/ Cervantes, s/n.E-37002 SALAMANCA. C. e.: danijs@usal.es
}

1 Este trabajo se ha realizado en el marco de una ayuda FPU (FPU15/01675) por el Ministerio de Educación, Cultura y Deporte.

Abreviaturas: Rotense / Sebastianense / Albeldense = Gil Fernández, Juan; Moralejo, José Luis y Ruiz de la Peña Solar, Juan Ignacio. Crónicas asturianas. Oviedo: Universidad de Oviedo, 1985; Sampiro = PÉREZ DE URBel, Justo. Sampiro, su crónica y la monarquía leonesa en el siglo X. Madrid: Consejo Superior de Investigaciones Científicas, 1952; CDCLII = SÁez SánCHEz, Emilio y SÁez SÁnChez, Carlos. Colección documental del archivo de la Catedral de León (775-1230). II (935-985). León: Centro de Estudios e Investigación San Isidoro, 1987; CDCLIII = RuIz Asencio, José Manuel. Colección documental del archivo de la Catedral de León (775-1230). III (986-1031). León: Centro de Estudios e Investigación San Isidoro, 1987; Dip. Astur = Floriano Cumbreño, Antonio C. Diplomática española del período astur: estudio de las fuentes documentales del Reino de Asturias. 3 vols. Oviedo: Instituto de Estudios Asturianos, 1949-1951; OD = Fernández Flórez, José Antonio y Herrero de la Fuente, Marta. Colección documental del monasterio de Santa María de Otero de las Dueñas. Vol. I (854-1 108). León: Centro de Estudios e Investigación San Isidoro, 1999; Eslonza = Ruiz Asencio, José Manuel y RuIz Albi, Irene. Colección documental del monasterio de San Pedro de Eslonza. Vol. I (912-1300). León: Centro de Estudios e Investigación San Isidoro, 2007; PMH, DC = Portugaliae monumenta historica a saeculo octavo post Christum usque ad quintumdecimum. Diplomata et chartae. Vol. I. Nendeln: Kraus Reprint, 1967 (1. a ed. 1867); PMH Script = Portugaliae monumenta historica a saeculo octavo post Christum usque ad quintumdecimum. Scriptores. Vol. I. Nendeln: Klaus Reprint, 1967 (1. a ed. 1867); Cron. Emires = IbN HaYYan. Crónica de los emires Alhakam I y Abdarrahman II entre los años 796 y 847 [Almuqtabis II-1] (traducción y edición de Mahmud Ali Makki y Federico Corriente). Zaragoza: Universidad de Zaragoza, 2001; Dikr = Mounna Martínez, Luis. «Las campañas de Almanzor a la luz de un nuevo texto». Al-Qantara, 1981, vol. 2, n.o 1, pp. 210-263; Al-Kardabus = IBn Al-Kardabus. Historia de Al-Andalus (traducción y notas de Felipe Maíllo Salgado). Madrid: Akal, 2008. 
CASTILLOS, CASTROS Y FORTALEZAS DURANTE LA EXPANSIÓN DEL REINO DE LEÓN. PODER Y FUNCIONES EN LA MONTAÑA LEONESA Y EL INTERFLUVIO TÁVORA-CÔA (SIGLOS X-XI)

Recibido: 2017-04-05

Revisado: 2017-10-16

Aceptado: 2018-05-18

RESUMEN: Se plantea un estudio comparativo entre los castillos de la montańa leonesa y los situados en el interfluvio Távora-Côa, desde los inicios del siglo x hasta mediados del siglo xI. Se trata de dos zonas que guardan en común su reconocimiento hacia la autoridad regnante in Legione desde la segunda década del siglo $\mathrm{x}$, una realidad política cuya uniformidad, tantas veces defendida por la historiografía institucionalista, únicamente se deja ver si tomamos los textos elaborados por el poder central al pie de la letra. A través de las fuentes documentales y del todavía muy deficiente registro material, se intenta dar luz sobre las funciones que los castillos de ambas regiones pudieron ejercer. Al mismo tiempo que se plantea la pregunta sobre la tipología y la identidad de los poderes activos en estos centros.

Palabras clave: Reino de León; Portugal; Montaña leonesa; Castillos; Territorialidad; Espacios de poder.

ABSTRACT: It is considered a comparative study of castles within the mountains of Leon and the Távora-Côa watershed from $10^{\text {th }}$ to middle $11^{\text {th }}$ Centuries. Two areas which had in common their recognition to the authority regnante in Legione from the second decade of $10^{\text {th }}$ Century. A political reality whose uniformity was supported by structuralist historiography, although it only can be appreciated if we consider texts emanated from central power in a literal way. Utilizing writing sources from the period combined with the deficient archaeological register, we try to alight on functions castles in these regions could have. At the same time, typology and identity of powers who were acting from all these centres are questioned.

Keywords: Kingdom of Leon; Portugal; Mountains of Leon; Castles; Territoriality; Spaces of power.

SUMARIO: 0 Introducción: el castillo como sujeto de estudio de la historiografía. 1 Los castillos de la montańa leonesa. 2 Más allá del Duero. Los castillos del interfluvio Távora-Côa. 3 Conclusiones: los castillos, una vía de análisis para las sociedades del noroeste de la Península Ibérica en la Alta Edad Media. 4 Referencias bibliográficas.

\section{INTRODUCCIÓN: El CASTILLO COMO SUJETO DE ESTUDIO DE LA HISTORIOGRAFÍA}

El estudio de los castillos como manifestación física del poder se ha visto potenciado gracias a la labor casi simultánea, aunque sin contactos directos apreciables, de 
CASTILLOS, CASTROS Y FORTALEZAS DURANTE LA EXPANSIÓN DEL REINO DE LEÓN. PODER Y FUNCIONES EN LA MONTAÑA LEONESA Y EL INTERFLUVIO TÁVORA-CÔA (SIGLOS X-XI) DANIEL JUSTO SÁNCHEZ

las escuelas historiográficas francesa ${ }^{2}$ y británica ${ }^{3}$. El objeto de estudio es, en ambos casos, el castillo entendido en un sentido amplio, pero los contextos originalmente analizados fueron diferentes. En Francia los estudios partieron del periodo post-carolingio, mientras que la historiografía británica se centró en el análisis de los castillos en la Inglaterra normanda. Su desarrollo posterior ha sido mayor para los periodos pleno y bajo medievales ${ }^{4}$ hasta que, en los últimos quince años, se han sumado trabajos que llevan este marco teórico a cronologías altomedievales, destacando la figura de Creighton ${ }^{5}$. Una traslación de enfoques que se traba con la problemática derivada de las condiciones físicas en las que suelen encontrarse los castillos del periodo: muchos de ellos presentan escasos restos que permanecen sin excavar de manera intensiva, mientras que los que han llegado en mejores condiciones han sufrido enormes transformaciones posteriores.

Por otro lado, el estudio de la territorialidad del espacio fortificado se enmarca en los amplios debates que, en torno al concepto de incastellamento, analizaron el desarrollo y la propia existencia del feudalismo mediterráneo. Sus orígenes se establecen con los estudios sobre el Lacio de Toubert ${ }^{6}$, cuya influencia sigue latente en la práctica totalidad de trabajos sobre la feudalización del territorio. Al mismo tiempo, a pesar de que sus trabajos no manejaban el registro material, influyeron notablemente en el surgimiento de una "arqueología del feudalismo" ${ }^{7}$, configurando un debate entre historiadores y arqueólogos capaz de reformular la visión del castillo como centro territorial de poder. El incastellamento habría supuesto una ruptura profunda con las formas de poblamiento y la estructura agraria, configurando el modelo de transformación mediterránea que fue capaz de "convertir a los campesinos en aldeanos» ${ }^{8}$. Wickham defendió un menor peso de los señores en las empresas de incastellamento y una mayor autonomía de las comunidades campesinas, además de criticar el lugar

2 Fournier, Gabriel. Le château dans la France médiévale. Essai de sociologie monumentale. Paris: Aubier Montaigne, 1978; Debord, André. Aristocratie et pouvoir. Le rôle du château dans la France médiévale. Paris: Picard, 2000.

3 Coulson, Charles L. H. «Structural symbolism in Medieval Castle architecture». Journal of the British Archeological Association, 1979, vol. 132, pp. 73-90; KInG, David J. C. Castellarium Anglicanum. New York: International Publications, 1983; Liddiard, Robert. Castles in context. Power, symbolism and landscape. 1066 to 1500. Macclesfield: Windgather Press, 2005.

4 Johnson, Matthew. Behind the castle gate: from Medieval to Renaissance. London: Routledge, 2002; Coulson, Charles L. H. Castles in medieval society: fortresses in England, France, and Ireland in the Central Middle Ages. Oxford-New York: Oxford University Press, 2003.

5 Creighton, Oliver H. Castles and landscapes: power, community and fortification in medieval England. London: Oakville, 2002, y Early European castles: aristocracy and authority, AD 800-1200. London: Bloomsbury, 2012.

6 Toubert, Pierre. Les structures du Latium médiéval. Le Latium méridional et la Sabine du IX siècle à la fin du XII siècle. Roma: École Française de Rome, 1973.

7 Quirós Castillo, Juan Antonio. El incastellamento en el territorio de la ciudad de Lucca (Toscana): poder y territorio entre la Alta Edad Media y el siglo XII. Oxford: BAR, 1999, p. 3.

8 Toubert, Pierre. Castillos, señores y campesinos en la Italia medieval. Barcelona: Crítica, 1990, p. 203. 
CASTILLOS, CASTROS Y FORTALEZAS DURANTE LA EXPANSIÓN DEL REINO DE LEÓN. PODER Y FUNCIONES EN LA MONTAÑA LEONESA Y EL INTERFLUVIO TÁVORA-CÔA (SIGLOS X-XI)

central otorgado por Toubert al siglo $\mathrm{x}^{9}$, adelantando en el tiempo el estadio nuclear de cambio a los alrededores del 800, especialmente a la luz de los datos arqueológi$\cos ^{10}$. Actualmente se ha llegado al convencimiento de la imposibilidad de aplicar el modelo toubertiano a gran escala sin modificaciones que lo adapten a las muy diversas realidades regionales.

Ninguno de estos marcos teórico-metodológicos fue aplicado al noroeste de la Península Ibérica hasta un momento muy tardío. Primero fue necesario todo un replanteamiento del marco teórico de la Alta Edad Media, a través de la obra de autores como Martínez Sopena, García de Cortázar o Mínguez Fernández ${ }^{11}$. Ya Reyna Pastor defendió la importación de los marcos teórico-metodológicos desarrollados fuera de la Península Ibérica, defendiendo la necesidad de desarrollar análisis más exhaustivos en el noroeste peninsular a pesar de que las condiciones sociales fueran diferentes ${ }^{12}$. Siguiendo esta misma línea se han publicado trabajos como el de Martín Viso, que abogan por una diferenciación de espacios para un mejor conocimiento de los procesos de feudalización en cada uno de ellos ${ }^{13}$.

Hasta el momento, Gutiérrez González destaca como uno de los máximos exponentes en el análisis del papel de las fortificaciones en la expansión de los reinos cristianos del norte ${ }^{14}$. Según sus teorías, asistiríamos a la presencia de castillos íntimamente ligados a la actividad de la monarquía, al tiempo que actúan como «núcleos centrales jerarquizadores de la estructura de poblamiento y articuladores de los espacios que presiden $»^{15}$. Los últimos años han sido muy fructíferos en la investigación

9 Wickham, Chris. «A che serve l'incastellamento?». En Barceló, Miquel y Toubert, Pierre (dirs.). L'incastellamento: actas de las reuniones de Girona, 26-27 noviembre 1992, y de Roma, 5-7 mayo 1994. Roma: École Française de Rome-Escuela Española de Historia y Arqueología en Roma, 1998, pp. 31-41.

10 Marazzi, Federico; Potter, Tim W. y King, Anthony. «Mola di Monte Gelato (Mazzano Romano - VT): notizie preliminari sulle campagne di scavo 1986-1988 e considerazioni sulle origini dell'incastellamento in Etruria Meridionale alla luce di nuovi dati archeologici». Archeologia Medievale, 1989, vol. 16, pp. 103-120; Hodges, Richard. Light in the Dark Ages: The rise and fall of San Vincenzo al Volturno. London: Cornell University Press, 1997; Francovich, Ricardo. «L'incastellamento e prima dell'incastellamento». En Barceló y Toubert (dirs.), L'incastellamento, pp. 13-20; Francovich, Ricardo y Hodges, Richard. Villa to village: the transformation of the Roman countryside. London: Bloomsbury, 2003.

11 Martínez Sopena, Pascual. La Tierra de Campos occidental: poblamiento, poder y comunidad del siglo X al XIII. Valladolid: Institución Cultural Simancas, 1985; GarCÍA DE CorTÁZAR, José Ángel. La sociedad rural en la España medieval. Madrid: Siglo XXI, 1988; Mínguez Fernández, José María. «Innovación y pervivencia en la colonización del valle del Duero». En Despoblación y colonización del Valle del Duero: siglos VIII-XX. Ávila: Fundación Sánchez-Albornoz, 1995, pp. 45-80.

12 Pastor De Togneri, Reyna. «Formación y consolidación del feudalismo castellano-leonés. Siglos X-XiII». En Malpica Cuello, Antonio y Quesada Quesada, Tomás (eds.). Los orígenes del feudalismo en el mundo mediterráneo. Granada: Universidad de Granada, 1994, pp. 317-331.

13 Martín Viso, Ińaki. «Riflessioni sull'incastellamento nella Penisola Iberica: la Castiglia dell'Ebro e la transierra di Madrid». Archeologia Medievale, 2001, vol. 28, pp. 83-107.

14 Gutiérrez González, José Avelino. Fortificaciones y feudalismo en el origen y formación del reino leonés (siglos IX-XIII). Valladolid: Universidad de Valladolid, 1995.

15 Gutiérrez González, José Avelino. "La implantación feudal y las fortificaciones en los orígenes del Reino de León». En Huerta Huerta, Pedro Luis (coord.). Actas del IV Curso de Cultura 
CASTILLOS, CASTROS Y FORTALEZAS DURANTE LA EXPANSIÓN DEL REINO DE LEÓN. PODER Y FUNCIONES EN LA MONTAÑA LEONESA Y EL INTERFLUVIO TÁVORA-CÔA (SIGLOS X-XI) DANIEL JUSTO SÁNCHEZ

historiográfica sobre los castillos como espacios de poder, especialmente cuando arqueología e historia han ido en la misma dirección. Se han mostrado especialmente eficaces los estudios sobre espacios reducidos, entre los que destacan los de Quirós Castillo en la región de Treviño ${ }^{16}$, el de Gutiérrez González sobre Peñaferruz (Gijón) ${ }^{17}$, las recientes investigaciones de Carvajal Castro ${ }^{18}$ en el entorno de Valdoré y en los valles del Cea y el Pisuerga, o la tesis de Pérez Rodríguez ${ }^{19}$ para Tierra de Campos. Por su parte, los estudios en Portugal presentan sus características propias, muy ligados a la menor importancia en términos relativos de estudios sobre la Edad Media portuguesa anterior al establecimiento del reino independiente en el siglo XII. Destaca la figura de Barroca, quien ha trabajado el tema desde los años noventa ${ }^{20}$. También sería interesante señalar los estudios regionales desarrollados por Afonso y Tente, muy útiles para conocer mejor la organización socio-espacial de los territorios portugueses en uno de sus periodos peor conocidos ${ }^{21}$.

Siguiendo esta línea, se plantea el estudio de las regiones del interfluvio TávoraCôa y de la montaña leonesa (véase figura 1). Dos zonas cuyo elemento en común más claro durante la cronología abordada era el reconocimiento de la autoridad de la monarquía regnante in Legione. Ahora bien, cada una desde las posiciones que ocupaban en la geografía del reino, la primera en una situación fronteriza frente a al-Ándalus y la segunda desde una retaguardia, eso sí, relativamente expuesta, como manifiestan las campañas de Almanzor a finales del siglo x. La perspectiva comparada nos permitirá comprobar si la edificación y el empleo de castillos como centros territoriales son

Medieval: Seminario, la fortificación medieval en la Península Ibérica: Centro de Estudios del Románico, Aguilar de Campoo, 21-26 de septiembre de 1992. Aguilar de Campoo: Fundación Santa María La Real, 2001, pp. 81-102, p. 91

${ }_{16}$ Quirós Castillo, Juan Antonio. «L'eccezione che conferma la regola? Incastellamento nella valle dell'Ebro nel x secolo: il castello di Treviño». Archeologia Medievale, 2011, vol. 38, pp. 113-136.

17 Gutiérrez González, José Avelino. Peñaferruz (Gijón). El castillo de Curiel y su territorio. Gijón: VTP Editorial, 2003.

18 Carvajal Castro, Álvaro. «Sociedad y territorio en el norte de León: Valdoré, los Flaínez y el entorno del alto Esla (siglos IX-XI)». Studia Historica. Historia Medieval, 2013, vol. 31, pp. 105-131; y, especialmente, «Los castros de la meseta del Duero y la construcción de la monarquía asturleonesa: el caso de Melgar en el siglo X». En Paisagens e poderes no Medievo Ibérico: actas do Encontro Ibérico de Jovens Investigadores em Estudos Medievais-Arqueologia, História e Património. Braga: Centro de Investigação Transdisciplinar "Cultura, Espaço e Memória» da Universidade do Minho, 2014, pp. 11-29.

19 Pérez Rodríguez, María. Jerarquización territorial y escenarios de poder en la cuenca del Duero: los valles benaventanos, los valles leoneses y el bajo Cea (siglos X-XII). Salamanca: Universidad de Salamanca, 2015 [tesis doctoral inédita].

20 Barroca, Mario Jorge. «Do castelo da Reconquista al castelo românico (Séc. IX a XII)». Portugalia. Nova Série, 1990-1991, vol. XI-XII, pp. 89-134; y «Fortificaçoes e Povoamento no Norte de Portugal (Séc. IX a XI)». Portugalia. Nova Série, 2004, vol. XXV, pp. 181-203.

${ }_{21}$ Afonso Vieira, Marina. «Reflexóes em torno do povoamento alto medieval da bacia superior do rio Paiva». En Martín Viso, Ińaki (ed.). ¿Tiempos oscuros? Territorios y sociedad en el centro de la Peninsula Ibérica (siglos VII-X). Madrid: Sílex, 2009, pp. 93-105. Tente, Catarina. «Viver em autarcia. A organizaçao do territorio do alto Mondego (Portugal) entre los séculos V a X». En Martín Viso (ed.), ¿Tiempos oscuros?, pp. 137-157. 
CASTILLOS, CASTROS Y FORTALEZAS DURANTE LA EXPANSIÓN DEL REINO DE LEÓN. PODER Y FUNCIONES EN LA MONTAÑA LEONESA Y EL INTERFLUVIO TÁVORA-CÔA (SIGLOS X-XI)

elementos ligados exclusivamente a la expansión del reino de León hacia el sur o si, por el contrario, manifiestan una mayor complejidad a la hora de identificar los sujetos políticos presentes en ellos.

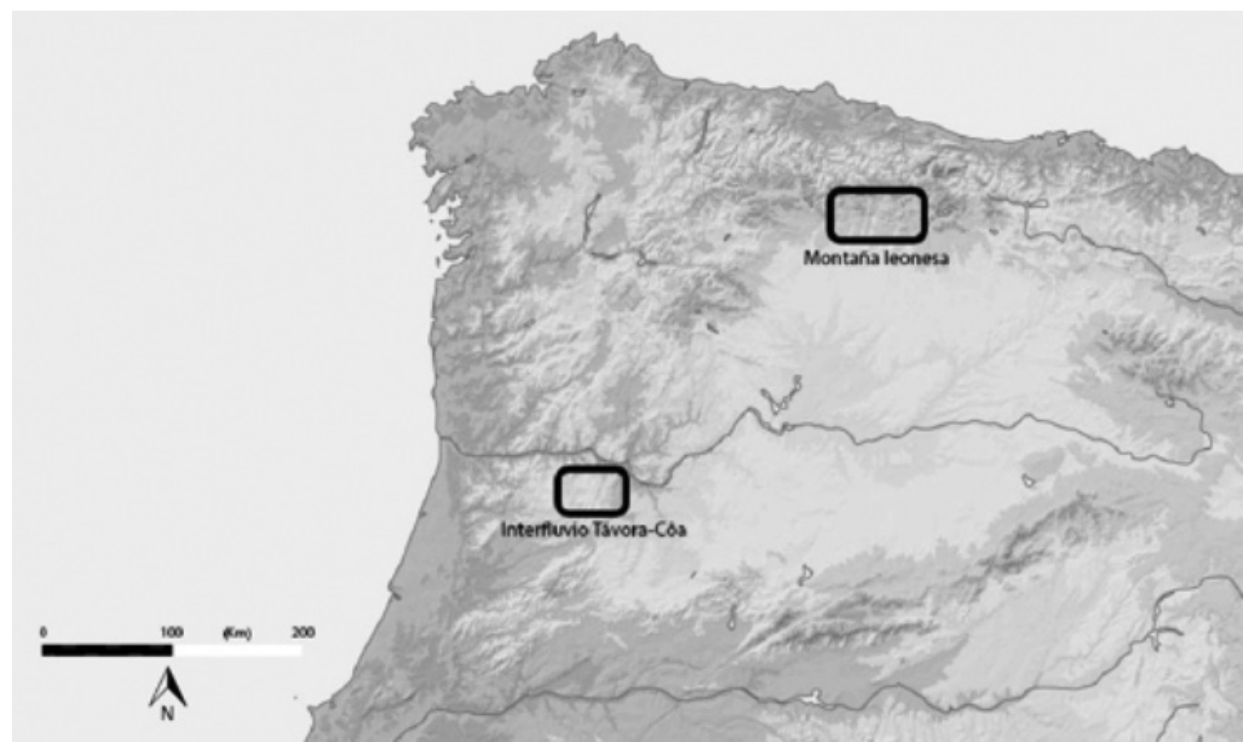

Figura 1. Regiones de estudio seleccionadas (elaboración propia).

\section{Los CASTILLOS DE LA MONTAÑA LEONESA ${ }^{22}$}

En 872, según la interpolación pelagiana de la crónica de Sampiro, Alfonso III mandó erigir una serie de castillos en el área de la montaña leonesa, entre ellos los de Luna, Gordón y $\mathrm{Alba}^{23}$. El hecho de disponer de espacios concretos desde los cuales dominar -incluso visualmente- el paisaje de alrededor habría sido fundamental para aquellos actores políticos que, como la monarquía asturleonesa de la segunda mitad del siglo Ix, pretendieran una reorganización hacia estructuras territoriales jerarquizadas claramente definidas. En estos procesos jugarían un papel fundamental las estructuras fortificadas, que aprovecharían puntos estratégicos de control de condiciones defensivas óptimas, como aquellas proporcionadas por los valles montañosos. Estos centros de poder habrían servido como base para el avance de los grupos en proceso de feudalización hacia el valle del Duero. De esta forma, los asentamientos de planta militar en estas zonas se han relacionado con dos fenómenos al mismo tiempo: la necesidad de establecer enclaves

22 Véanse Tabla 1 y Figura 2.

23 «Fecit eciam castella plurima, et ecclesias multas, sicut hic subscriptum est: in territorio Legionensi Lunam Gordonem et Aluam», Sampiro, $\$ 2$. 
CASTILLOS, CASTROS Y FORTALEZAS DURANTE LA EXPANSIÓN DEL REINO DE LEÓN. PODER Y FUNCIONES EN LA MONTAÑA LEONESA Y EL INTERFLUVIO TÁVORA-CÔA (SIGLOS X-XI) DANIEL JUSTO SÁNCHEZ

militares para asentar la conquista y como un mecanismo de intensificación del poder real en la zona ${ }^{24}$. No obstante, es preciso valorar la medida en que cada uno de estos dos fenómenos actúa sobre los castillos en su conjunto.

Así como las fuentes de las que disponemos para cada una de las regiones estudiadas difieren en calidad y accesibilidad, también es variable la frecuencia con la que encontramos noticias para los distintos castillos mencionados en el registro escrito. Las intervenciones arqueológicas, que tan decisivas han sido para la evolución de las interpretaciones en otros espacios europeos, apenas han sido desarrolladas en casos de la montaña leonesa, si bien se espera que este tipo de intervenciones puedan surgir en León con mayor potencia de la que han tenido por el momento. A pesar de esta falta de intervenciones arqueológicas intensivas, Gutiérrez González sí pudo identificar a partir del registro arqueológico encontrado una variante en la estratificación social de los distintos castillos de la región. Mientras que casos como San Emiliano, Mallo de Luna o La Valcueva carecen de elementos que puedan dar muestras de la existencia de estratificación social en época altomedieval, los castillos de Llanos de Alba o Gordón, a través de la construcción de torres prominentes, sí manifestarían una pujante diferenciación social ${ }^{25}$. La documentación de los siglos $\mathrm{x}$ y XI nos permite, si bien a través de escasas noticias, valorar algunas de las funciones que estos castillos tuvieron, aunque es preciso relativizar la representatividad que esta serie de noticias concretas pueda tener para el conjunto de la montaña leonesa, mucho más para regiones más amplias.

\begin{tabular}{|l|l|l|}
\hline Nombre & Otras terminologías en la documentación & Término municipal actual \\
\hline Llanos de Alba & Castillo de Alba & La Robla \\
\hline Los Barrios de Luna & Castillo de Luna & Los Barrios de Luna \\
\hline San Salvador de Curueńo & $\begin{array}{l}\text { Castellum Sancti Salvatore, Castrum Curonio, } \\
\text { Castillo de Curueño }\end{array}$ & Santa Colomba de Curueńo \\
\hline Aviados & & Aviados (Valdepiélago) \\
\hline Acebedo & & Acebedo \\
\hline Valmartino & & Valmartino, Cistierna \\
\hline La Valcueva & & La Valcueva-Matallana de Torío \\
\hline Los Barrios de Gordón & Castillo de Gordón & Los Barrios de Gordón-Pola de Gordón \\
\hline San Martín de la Falamosa & Castillo de Aquilar & San Martín de la Falamosa-Las Omańas \\
\hline Mallo de Luna & & Mallo de Luna-Los Barrios de Luna \\
\hline San Emiliano & & San Emiliano \\
\hline Bońar & Balneare & Bońar \\
\hline
\end{tabular}

24 Carvajal Castro, Álvaro. "Castra and castella as symbols of power and authority in early Medieval León $\left(9^{\text {th }}-11^{\text {th }}\right.$ c.)» [en prensa]. Agradezco al autor el haberme permitido acceder al artículo con anterioridad a su publicación.

25 Debemos tener en cuenta que ninguno de los dos emplazamientos presenta restos claramente visibles del alzado de las torres altomedievales mencionadas en Gutiérrez González, José Avelino. «La fortificación pre-feudal en el norte peninsular. Castros y recintos campesinos en la Alta Edad Media». En Mil Anos de Fortificaçoes na Península Ibérica e no Magreb (500-1500). Simpósio Internacional sobre Castelos. Lisboa: Ediçóes Colibrí, 2002, p. 25. 
CASTILLOS, CASTROS Y FORTALEZAS DURANTE LA EXPANSIÓN DEL REINO DE LEÓN. PODER Y FUNCIONES EN LA MONTAÑA LEONESA Y EL INTERFLUVIO TÁVORA-CÔA (SIGLOS X-XI)

\begin{tabular}{|l|l|l|}
\hline Nombre & Otras terminologías en la documentación & Término municipal actual \\
\hline Colle-Vozmediano & Castellum Collem & Bońar \\
\hline Sabero & Castello Aquilare, Castrum Aguilar & Sabero-Cistierna \\
\hline Redipollos & & Redipollos-Puebla de Lillo \\
\hline Las Salas & Castillo de Alion & Las Salas-Riaño \\
\hline Riańo 1 & Castello de Rianno & Riańo \\
\hline Riaño 2 & Torre de Riaño & Riańo \\
\hline Siero de la Reina & Castillo Siero & Siero de la Reina \\
\hline Morgovejo-Prioro & Castillo de Peñafiel & Morgovejo-Prioro \\
\hline Fuentes de Peñacorada & Castro Monteacuto, Castello Monteacuto & Fuentes de Peñacorada, Cistierna \\
\hline Prioro-La Red & Castello Ferraria, Castello Herrera de Rianno & Prioro-La Red \\
\hline Castro Pelayo & Castrum Pelagii & Valdoré \\
\hline
\end{tabular}

Tabla 1. Castillos de la montaña de León identificados en la documentación escrita y a partir del registro material (elaboración propia a partir de Gutiérrez GonzÁlez, Fortificaciones y feudalismo).

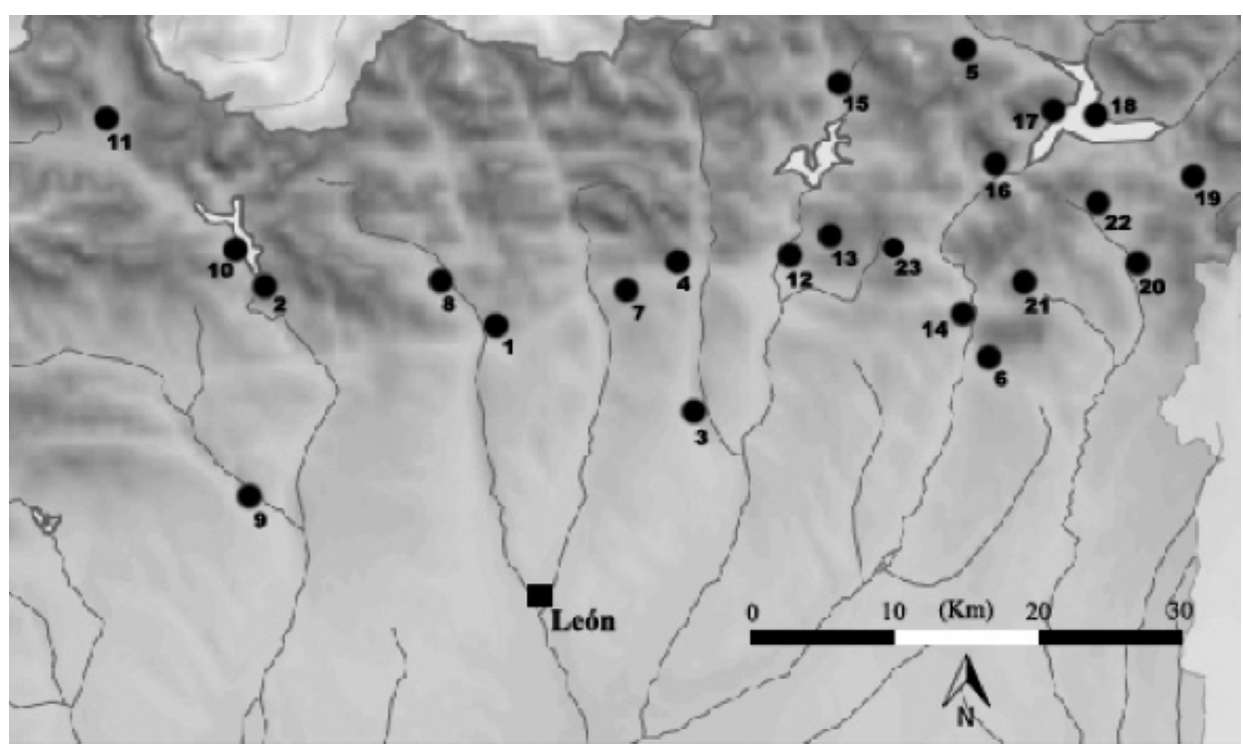

Figura 2. Mapa de la montaña leonesa con la localización de los castillos identificados en la Tabla 1 (elaboración propia). Leyenda: 1-Llanos de Alba, 2-Los Barrios de Luna, 3-San Salvador de Curueño, 4-Aviados, 5-Acebedo, 6-Valmartino, 7-La Valcueva, 8-Los Barrios de Gordón, 9-San Martín de la Falamosa, 10-Mallo de Luna, 11-San Emiliano, 12-Bońar, 13-Colle-Vozmediano, 14-Sabero, 15-Redipollos, 16-Las Salas, 17-Riaño 1, 18-Riaño 2, 19-Siero de la Reina, 20-Morgovejo-Prioro, 21-Fuentes de Peñacorada, 22-Prioro-La Red, 23-Castro Pelayo.

Para comenzar, es rastreable para algunos castillos de la montaña leonesa su función como centros de circunscripciones territoriales delegadas del poder regio asturleonés, en relación con términos como mandatio. En el caso de Luna, un documento sobre el que 
CASTILLOS, CASTROS Y FORTALEZAS DURANTE LA EXPANSIÓN DEL REINO DE LEÓN. PODER Y FUNCIONES EN LA MONTAÑA LEONESA Y EL INTERFLUVIO TÁVORA-CÔA (SIGLOS X-XI) DANIEL JUSTO SÁNCHEZ

luego volveremos nos sitúa ante una serie de confiscaciones realizadas en 1016 por Alfonso $\mathrm{V}$ a Fromárigo Sendíniz ${ }^{26}$. El propio trasfondo nos permite deducir que la mandación de Luna debía ser anterior, fenómeno que puede apoyarse documentalmente, aunque de manera mucho más débil, en las menciones de Luna empleando la fórmula infra castello ${ }^{27}$. La situación podría quedar más clarificada si se diera por buena la más temprana de las noticias: una donación de Alfonso III y su esposa Jimena a la iglesia de San Adriano de Tuñón de varias villas, entre ellas la de Falamosa, y la iglesia de San Martín, en territorio de Luna y de Aguilar ${ }^{28}$. Esta noticia también podría servirnos para señalar la existencia de Aquilar como un centro territorial de la época. Sin embargo, la falta de menciones más evidentes -o de autenticidad incuestionable- similares a las que hay para el caso de Luna, nos impide afirmar la existencia de un castillo en este territorio. Efectivamente, la existencia de un territorio no significa necesariamente que este tenga un castillo, pues sabemos que no son los únicos potenciales centros de poder. Estas menciones, junto con aquellas que emplean la fórmula subtus castello, pueden ser indicios de estructuras jerárquicas en torno a los castillos. Sin embargo, para comprobar esta hipótesis sería necesario un estudio extensivo a mayor escala, para valorar el significado y volumen real de noticias.

Otro caso útil para el particular es el de San Salvador de Curueńo, relacionado junto a sus mandationes en la donación de Ordońo III al obispo Gonzalo de León ${ }^{29}$. Este documento nos muestra cómo el espacio de Curueńo ya tenía una estructura

26 «Adhuc magis inantamus illuc et dedimus Luna et Uadabbia cum omnium mandamentum eorum ad intecrum», CDCLIII, doc. 741.

27 Tenemos un ejemplo en la mención de Luna, junto al cercano castillo de Gordón, en una donación de Ordoño II en 918 al obispo Fruminio (CDCLII, doc. 44). El hecho de que el documento haya llegado a través de dos copias de los siglos XVI y XVII, en un texto sumamente deformado y con descripciones de límites en lenguaje de evolución avanzada, a lo menos del siglo XIII, nos obliga a marcarlo como profundamente interpolado. En estas circunstancias, la unicidad de la noticia sobre Gordón no nos parece suficiente para afirmar su capacidad como centro territorial en el siglo x. Sin embargo, para el caso de Luna sí nos podría servir como refuerzo, aunque tenue, a la hipótesis de que ya ejerciera un papel como centro territorial durante el siglo $\mathrm{x}$, tomando en consideración lo expuesto en relación con la nota anterior.

28 «Offerimus eiusdem ecclesie uestre uillas nostras proprias pernominatas idest [...] in territorio Aquilare et de Luna uilla Falamosa», Dip. Astur, doc. 143. El debate que ha existido entre los especialistas en torno a la autenticidad del documento nos obliga, cuanto menos, a manejarlo con sumo cuidado. Aparece transcrito a partir de su supervivencia más antigua, la copia del siglo XIV incluida en el Libro de la Regla Colorada, uno de los trece códices diplomáticos fundamentales que se guardan en la catedral de Oviedo. Sánchez-Albornoz consideró la donación auténtica, mientras que Barrau-Dihigo subrayó las interpolaciones del documento, especialmente en el dispositivo. En Rodríguez Díaz, Elena E. El Libro de la Regla Colorada de la catedral de Oviedo, estudio y edición. Oviedo: Real Instituto de Estudios Asturianos, 1995 -la más reciente edición de la Regla Colorada-, la editora señala la existencia de una versión pseudo-original en la Crónica General de España, de Ambrosio de Morales (siglo xvi), siendo el texto de la Regla Colorada una copia del Libro de los Privilegios. Dicho esto, más allá de que ambas copias presentan la data incorrecta (dando la autora finalmente por buena la datación de Floriano en 891), no ha sido posible identificar ninguna falsificación o interpolación.

29 «Castellum quos uocitant Sancti Salbatore, qui est super ripa crepidinis aluey Curonio, quom mandationibus suis» (CDCLII, doc. 300). 
CASTILLOS, CASTROS Y FORTALEZAS DURANTE LA EXPANSIÓN DEL REINO DE LEÓN. PODER Y FUNCIONES EN LA MONTAÑA LEONESA Y EL INTERFLUVIO TÁVORA-CÔA (SIGLOS X-XI)

(10) DANIEL JUSTO SÁNCHEZ

territorial dependiente a mediados del siglo $\mathrm{x}$, si bien esta no se denomina territorium ${ }^{30}$. A inicios del siglo XI Curueño aparece en la documentación bajo la denominación de mandatio, lo que nos transmite una idea acerca de la mutabilidad de los conceptos al referirse a los centros territoriales en el reino de León, al menos durante el periodo estudiado ${ }^{31}$. Este fenómeno parece confirmarse cuando apreciamos espacios concretos como Ferreras, denominado mandatio dependiente de Curueño en algunos documentos mientras que en otros cercanos en el tiempo aparecerá bajo la denominación de comisso $^{32} \mathrm{o}$ incluso de territorio ${ }^{33}$. Esta diversidad terminológica manifiesta cómo la dependencia entre espacios todavía es bastante difusa.

La situación se complica cuando encontramos menciones que evidencian una dependencia territorial en torno a un centro identificable con un castillo, sin que el emplazamiento sea reflejado literalmente como tal. Este es el caso de Bońar, marcado como centro de un territorium en 929, cuando el conde Gisvado y su mujer Leuvina, donan al monasterio de San Adrián y Santa Natalia una villa «que est situm in territorio Balneare ${ }^{34}$. La relación castral aparece en este caso en el documento de fundación y dotación del monasterio, que también tiene por protagonistas a Gisvado y su esposa. En este, el territorio de Boñar aparece relacionado con un "castellum anticum», que actuaría como marcador territorial ${ }^{35}$. Aunque no podemos descartar por completo que la mención al castillo antiguo sea una mera reminiscencia en forma de memoria del poder, nos inclinamos por pensar que sí tendría relación directa con la presencia de un centro territorial en forma de castillo y que no es una casualidad la coincidencia geográfica entre ambas realidades.

Estas menciones podrían fácilmente ser interpretadas, teniendo en cuenta una estructura territorial claramente definida, como un simple mandato regio a uno de sus subalternos, a quien entregaba una circunscripción territorial concreta para un mejor control del territorio y una más eficaz exacción de impuestos. Ahora bien, si tenemos en cuenta la complejidad de la estructura territorial que se aprecia para el reino de León con posterioridad a la expansión sobre los territorios al sur de la Cordillera Cantábrica, el papel del castillo como centro de un territorio concreto no varía, pero la actitud del monarca y el propio sentido del territorio sí pueden hacerlo. Esta tendencia se puede relacionar con las menciones a cobro de tributum o censum en diversos centros de poder por mandato regio, al tiempo que los delegados también cobraban rentas propias ${ }^{36}$. Todo ello, combinado, nos transmite una imagen de enorme complejidad, en la que el castillo aparece como una pieza importante de las relaciones de poder.

30 El mismo fenómeno que se manifiesta en la donación de 999, donde se hace mención a: «castellum quam uocitant Sancto Salbatore qui est in Curonio quum mandationibus suis» (CDCLII, doc. 300); y en otra de Alfonso V en 1012: «hunc locum kastellum quam dicunt Sancto Salbatore [...] ipsum kastrum cum suis mandationibus» (CDCLII, doc. 700).

31 "Mandationes adcomendatas, de uobis Petru Flainizi, Curonio / et Lorma et Ferreras» (OD, doc. 136).

32 CDCLII, doc. 577.

33 CDCLII, doc. 680.

34 Eslonza, doc. 7.

35 Eslonza, doc. 9.

36 Tenemos un ejemplo sobre el cobro de este tipo de rentas en $O D$, doc. 136. 
CASTILLOS, CASTROS Y FORTALEZAS DURANTE LA EXPANSIÓN DEL REINO DE LEÓN. PODER Y FUNCIONES EN LA MONTAÑA LEONESA Y EL INTERFLUVIO TÁVORA-CÔA (SIGLOS X-XI) DANIEL JUSTO SÁNCHEZ

Desde comienzos del siglo x parece producirse un replanteamiento de los juegos de poder, al disminuir el número de menciones a fortificaciones asociadas directamente con el poder monárquico. Aparecen con fuerza las figuras de otros actores políticos en la zona, entre los que conviene destacar, además del monarca y los miembros de su curia, las familias Vermúdez y Flaínez; o particulares como el conde Gisvado. Dentro de las instituciones eclesiásticas es preciso mencionar a los monasterios de San Cosme y San Damián o el de San Adrián y Santa Natalia, si bien tiene una importancia particular la actividad de la sede catedralicia de León. En el siglo x, por lo tanto, los espacios de la montańa leonesa a los que nos aproximamos todavía no han conocido las grandes expansiones económicas de importantes monasterios como San Pedro de Eslonza o Sahagún, fundamentales para entender el juego de poderes en los siglos plenomedievales. Dentro de esta nómina, algunos actores políticos actuaron como delegados regios en la tenencia de un castillo.

Una buena muestra de este tipo de actuaciones la tenemos en la recurrente delegación real que, durante los siglos X-XI, encontramos para el caso de San Salvador de Curueńo en favor de la catedral de León. A mediados del siglo x, Ordońo III concedió el castillo con sus mandationes, y los hombres que las sirven, a la sede episcopal personificada en la figura del obispo Gonzalo ${ }^{37}$. En algún momento durante la segunda mitad del siglo x el castillo debió ser retomado por los monarcas, pues en 999 encontramos de nuevo su concesión a la sede leonesa con motivo de la coronación de Alfonso $\mathrm{V}^{38}$. Una nueva donación sería efectuada en 1012, cuando se nos muestra a Alfonso $\mathrm{V}$ devolviendo a la sede de León y a su obispo Nuño el castillo y sus dependencias, arrebatado al alcaide del mismo durante la insurrección de García Gómez ${ }^{39}$. Esta serie de concesiones nos habla de una relación directa entre el monarca en León y la iglesia de Santa María. El castillo de San Salvador debía ser un centro de poder cuyo control interesaba a los grandes poderes del momento: diversos territorios dependían de él, ejercía su control sobre importantes zonas de pasto y controlaba visualmente el valle del río Curueńo. Todo ello significaba un mayor acceso a las exacciones sobre los habitantes de la región y una mayor capacidad de control. Sin embargo, al parecer, los monarcas primaron su buena relación con la sede leonesa a un control directo de la zona. De este modo observamos cómo, a fin de equilibrar el peso de los magnates como agentes políticos fundamentales del reino y el reforzamiento de la propia monarquía, esta recurre a los castillos con el objeto de afianzar sus redes de influencia. Nos hallamos ante una delegación del poder reconocido al monarca sobre un determinado territorio, controlado por un castillo. Una acción que disminuye la capacidad de control directo del rey, pero contribuye a reforzar sus relaciones con los otros actores políticos de la región.

El mecanismo mediante el cual el monarca es capaz de reforzar sus relaciones con otros actores políticos, aparentemente simple si atendemos únicamente a la relación con uno de ellos, se vuelve mucho más complejo cuando apreciamos la coincidencia de poderes en un mismo espacio y las fricciones entre estos. El propio territorio de Curueño es

CDCLII, doc. 300.

CDCLIII, docs. 588 y 589.

39 CDCLIII, doc. 707. 
CASTILLOS, CASTROS Y FORTALEZAS DURANTE LA EXPANSIÓN DEL REINO DE LEÓN. PODER Y FUNCIONES EN LA MONTAÑA LEONESA Y EL INTERFLUVIO TÁVORA-CÔA (SIGLOS X-XI)

DANIEL JUSTO SÁNCHEZ

buena muestra de esta mayor complejidad, pues, aunque las concesiones a la catedral de León aparentemente dotarían a esta de exclusivo dominio sobre las dependencias de la zona, la realidad es que otros actores políticos actúan allí. En 1021, por ejemplo, encontramos a Fernando Braóliz, un delegado de Pedro Flaínez, encomendado a cobrar diversos derechos, entre otros las costas judiciales, en algunas de sus mandationes ${ }^{40}$. Este fenómeno, no obstante, no resulta tan extraño si tomamos en consideración que la vía judicial ha sido observada por algunas investigaciones recientes como un mecanismo eficaz para aumentar el poder de los magnates en determinadas áreas de León ${ }^{41}$.

Asistimos a un caso similar en 1011 en un pleito entre don Fernando, abad del monasterio de San Cosme y San Damián, y su vicario en Abelgas, García, con Frumarico Sendíniz, merino de Luna, y su vicario en ella, su hermano Elías. Estos pretendían que los hombres de Luna habían de servir al señor de Luna, y el abad, al monasterio. Llevada a cabo la pesquisa, se puso de manifiesto que desde tiempos del rey Ordońo II, que donó el lugar al monasterio de San Cosme y San Damián, los hombres de Abelgas no habían servido al señor de Luna ni al sayón. Así lo ratificaron mediante juramento tres monjes del monasterio, reconociendo Frumarico que carecía de derecho sobre los hombres de Luna $^{42}$. De nuevo observamos cómo Luna es un centro del que dependían otros espacios, si bien ahora el delegado del monarca allí es un notable laico, en contra de quien se resuelve el litigio. De esta forma, podemos observar que la territorialidad asociada a un centro fortificado concreto era relativamente débil o, al menos, un tanto difusa, pues existían litigios entre diferentes actores políticos que no se resolvían siguiendo patrones jurisdiccionales específicos, sino con soluciones ad hoc. Todo ello refleja que el poder regio era una suerte de elemento superior que convivía con otros tipos de dominio.

Existen también en la documentación alusiones a otras autoridades menores, que pudieran representar a las élites de las comunidades locales con cierto peso en la estructura de dominación territorial. Estos grupos sociales pudieron haber empleado espacios fortificados de segunda fila para reivindicar sobre el paisaje su pujanza social ${ }^{43}$. La erección de una fortificación que dominase -incluso visualmente- el área circundante pudo servir como símbolo de esta diferenciación social en construcción. De hecho, como ha señalado Carvajal Castro, es posible apreciar cómo la acción de estas élites de menor rango era muy importante en coyunturas como los levantamientos contra el poder regio, cuando los insurrectos buscaban su apoyo ${ }^{44}$. Este tipo de situaciones crean una aparente

40 OD, doc. 136.

41 Carvajal Castro, «Sociedad y territorio en el norte de León»; y Davies, Wendy. "Settling disputes in early medieval Spain and Portugal: a contrast with Wales and Brittany?». En Griffiths, Ralph Alan y Schofield, Phillipp R. (eds.). Wales and the Welsh in the Middle Ages. Cardiff: University of Wales, 2011, pp. 89-107.

42 CDCLIII, doc. 695.

43 Castillos que no se mencionan en la documentación como importantes centros territoriales y sobre los cuales la arqueología tiene el protagonismo casi exclusivo de rescatar.

44 Carvajal Castro, "Castra and castella» [en prensa]. Este tipo de apoyos y la reacción del monarca ante ellos puede verse, por ejemplo, en la sentencia de Vermudo II en 993, cuando se menciona el apoyo de un notable llamado Salvador al levantamiento de García Gómez (CDCLIII, doc. 559), o en el texto en el que se narra el apoyo del alcalde de Curueño al mismo (CDCLIII, doc. 707). 
CASTILLOS, CASTROS Y FORTALEZAS DURANTE LA EXPANSIÓN DEL REINO DE LEÓN. PODER Y FUNCIONES EN LA MONTAÑA LEONESA Y EL INTERFLUVIO TÁVORA-CÔA (SIGLOS X-XI) DANIEL JUSTO SÁNCHEZ

paradoja, pues el empleo de las élites locales para afianzar el poder regio provocaba que estos grupos se convirtieran en una herramienta que, correctamente empleada por los aristócratas insurrectos, les fuera útil en su empresa de obtener mayores cuotas de poder. Este papel de elemento intermedio en los juegos de poder suponía para los notables locales, a fin de cuentas, un aumento en su estatus, siempre y cuando sus decisiones coincidieran con la del sector vencedor en los conflictos. En el seno de las relaciones con la monarquía, el registro escrito nos permite vislumbrar el proceso a través del cual los miembros destacados de las comunidades locales aumentarían progresivamente su estatus. A pesar de que estas relaciones, sin duda, tomarían diferentes vías según la casuística, es posible resaltar el ejercicio de cargos subalternos, como el sayón ${ }^{45}$. De este modo, ciertos miembros destacados de las comunidades locales proporcionan el personal necesario para hacer efectivo el dominio que se plasma en los castillos, redundando este ejercicio, de forma simultánea, en un aumento del estatus de estos notables locales y en un afianzamiento de la autoridad regia en la zona.

A pesar de que los poderes coexistentes en la zona eran diversos, cabe destacar la capacidad última de los reyes para ejercer su dominio sobre el castillo y su territorio circundante. Así, aunque el monarca delega el control del castillo, su acceso no queda anulado ni su autoridad última superada. La delegación, producida tanto en personajes de la región como en gentes procedentes de fuera de León, no implica la pérdida del control del castillo por parte del rey. Este proceso se puede observar claramente en las concesiones que se vuelven a realizar como resultado de una insurrección, o en el propio acto de confiscación de bienes a un insurrecto ${ }^{46}$. Asimismo, la disponibilidad que el monarca tiene de sus castillos llega a algunas situaciones extremas, como el evento narrado por Sampiro en el que Ramiro II mandó encerrar al conde rebelde Diego Muñoz en el castillo de Gordón ${ }^{47}$.

Hemos visto cómo el registro escrito muestra una variedad de contextos donde los castillos jugaron diversos roles. Es relativamente escasa la presencia de actividad bélica directa en ellos, si bien es cierto que estos eventos podían estar implícitos en los conflictos internos relacionados con las insurrecciones magnaticias ${ }^{48}$. A las menciones documentales como marcadores territoriales, sirviéndose de su objetiva situación

45 Martín Viso, Iñaki. Poblamiento y estructuras sociales en el norte de la Peninsula Ibérica, siglos VI-XIII. Salamanca: Ediciones Universidad de Salamanca, 2000, p. 192.

46 Un buen ejemplo es la confiscación por Vermudo II en 998 sobre las propiedades de Gonzalo Vermúdez, rebelde desde el castillo de Luna. En ella se puede apreciar que el rey se refiere al castillo como «nostro castello que uogatur Luna» (CDCLIII, doc. 581), por lo que se entiende que el castillo no se encuentra entre las propiedades confiscadas: el castillo era propiedad última del rey y su autoridad era considerada superior a pesar de haberla delegado.

47 «His factis Fredenandus Gundissalui et Didacus Munionis contra regem dominum Ranimirum tirannidem gesserunt necnon et bellum parauerunt. Ille uero rex, ut erat prudens et fortis comprehendit eos, et unum in Legione, alterum in Gordone ferro uinctos carcere trusit» (Sampiro, \$23).

48 Por ejemplo, en el desarrollo de la insurrección de García Gómez, cuando los fieles a Alfonso V debieron apoderarse de la fortaleza de San Salvador de Curueño. CDCLIII, 707. Para el siglo Ix sí tenemos, en el contexto de la célebre rebelión de Mahamuth contra Alfonso II, una narración explícita de la campaña que debió desarrollarse contra el castillo de Santa Cristina (Sebastianense, \$22, 5-17, p. 141). 
CASTILLOS, CASTROS Y FORTALEZAS DURANTE LA EXPANSIÓN DEL REINO DE LEÓN. PODER Y FUNCIONES EN LA MONTAÑA LEONESA Y EL INTERFLUVIO TÁVORA-CÔA (SIGLOS X-XI)

DANIEL JUSTO SÁNCHEZ

destacada en el paisaje o de su pervivencia como centros de memoria, se suma su labor como centro territorial y como pieza en los juegos de poder entre los distintos actores políticos del momento.

\section{Más allá del Duero. Los castillos del interfluvio Távora-CôA}

Como el conjunto de la Beira Interior, nos situamos ante una región periférica respecto al poder central tanto durante el periodo romano como en la etapa visigoda. La caída del Reino de Toledo y la conquista musulmana, con el consiguiente y premeditado abandono por parte del poder emiral de los territorios del valle del Duero, provocaron la desaparición de toda autoridad superior centralizada en la región. Mattoso defendió una probable recuperación de antiguos hábitos de depredación, basados en la rivalidad entre poblados, que habrían llevado a una sensación de inseguridad generalizada y a la necesidad de concentrarse, para así procurarse lugares fáciles de defender. $\mathrm{Al}$ mismo tiempo, la actividad económica de estas comunidades, basada principalmente en la cría de ganado, motivaba una acuciante necesidad de establecer un cierto control sobre los pastos y una mejor protección a los animales ${ }^{49}$. $\mathrm{Al}$ mismo tiempo, dada su condición de frontera directa con al-Ándalus ${ }^{50}$, la región quedaba expuesta a mayor número de razias y operaciones de castigo, constituyendo además una zona de paso para campañas de mayor envergadura dirigidas desde Cáceres o Badajoz hacia fortalezas más septentrionales.

Esta situación, lejos de producir una masiva despoblación del territorio, provocó una adaptación en las comunidades locales ${ }^{51}$, de modo que en su avance hacia el sur la monarquía leonesa encontró una serie de espacios en los que se habían gestado fuertes poderes locales autónomos, políticamente invertebrados pero favorecedores de una situación de atomización política y territorial ${ }^{52}$. Estos procesos de integración se han valorado en los últimos años manejando el concepto de «islas de autoridad», según el cual, el poder de la monarquía leonesa plasmó el nuevo statu quo en una serie de lugares centrales desde los cuales se hacía presente la integración en el reino, proyectando la autoridad superior hacia el territorio circundante. Estos pivotes, para el caso del sur del Valle del Duero, toman nombre de grandes centros fortificados como Viseu, Salamanca o Sepúlveda, pero también de otros menores como Sacramenia, Portillo o Ledesma. Según esa teoría, la extensión de las nuevas relaciones políticas hacia las áreas adyacentes no fue uniforme y posiblemente en aquellos puntos que se situaban lejos de estos ganglios apenas se hacía

49 Mattoso, José. História de Portugal. Antes de Portugal. Lisboa: Editorial Estampa, I997, pp. 398 y 406

50 En el territorio del actual Portugal esta llegaba hasta el valle del Mondego en la fachada atlántica y hasta el valle del Côa en el interior. BARroca, Mario Jorge. «Aspectos da evoluçáo da arquitectura militar da Beira Interior». En Beira Interior: história e patrimonio. Actas das I Jornadas de Património da Beira Interior, 1-3 de Octubro de 1998. Guarda: Aprova, 2000, pp. 215-238, p. 216.

51 Mattoso, História de Portugal, pp. 406 y 416.

52 Afonso Vieira, «Reflexôes em torno do povoamento alto medieval»; y Tente, Catarina. «Settlement and society in the Upper Mondego Basin (Centre of Portugal) between the $5^{\text {th }}$ and the $11^{\text {th }}$ centuries». Archeologia Medievale, 2012, vol. 39, pp. 385-398. 
CASTILLOS, CASTROS Y FORTALEZAS DURANTE LA EXPANSIÓN DEL REINO DE LEÓN. PODER Y FUNCIONES EN LA MONTAÑA LEONESA Y EL INTERFLUVIO TÁVORA-CÔA (SIGLOS X-XI) DANIEL JUSTO SÁNCHEZ

presente la influencia asturleonesa ${ }^{53}$. De este modo, sería posible apuntar que la integración de estas zonas en los mecanismos de poder leoneses se desarrolló sobre una jerarquía territorial fluida, que presentaba un sistema de asentamientos con sus propias élites y poderes, con los que la monarquía tuvo que relacionarse.

El acercamiento a las funciones de las estructuras fortificadas de esta región puede servirnos para conocer mejor estos procesos. Conviene hacer referencia a la ausencia de noticias relativas a las fortificaciones de la zona anteriores a la época de Alfonso III, seguramente debido al déficit de poderes generadores de documentación en estos espacios. Teniendo en cuenta estos elementos, para analizar las estructuras fortificadas del interfluvio TávoraCôa en el siglo X ${ }^{54}$ es imprescindible recurrir a un documento muy destacado en el marco generalizado de ausencia de noticias. En 960, dońa Flámula dona una serie de posesiones, dado su grave estado de salud, al monasterio de Guimarães, antes de profesar como monja en él. Entre lo donado destacaba una serie de castillos, mencionados de la forma que sigue:

«Ordinamos nostros castellos id est Trancoso, Moraria, Longobria, Naunam, Uacinata, Amindula, Pena de Dono, Alcobria, Seniorzelli, Caria; cum alias penellas et populaturas que sunt in ipsa stremadura omnia uindere et pro remedio anime nostre captiuos et peregrinos et monasteria distribuere in ipsa terra ${ }^{55}$.

La ascendencia familiar de la donante ha sido cuidadosamente identificada por la investigación a lo largo de los ańos. Al tratarse de la hija de D. Rodrigo Tedones y de Leodegundia Díaz $z^{56}$ descendía de dos familias condales del norte: la del presor de Tuy, Alfonso Betotes, y la de Diego Fernández, poblador de la zona de Lamego ${ }^{57}$. Era también sobrina de Mumadona Díaz ${ }^{58}$, lo que liga a Flámula con el monasterio de Guimarães en tanto su tía fue la fundadora del cenobio. Es importante puntualizar que la presencia patrimonial del monasterio en el interfluvio Távora-Côa es una notable excepción a su tendencia expansiva, centrada hacia el sureste en el control sobre el área más poblada de los valles y colinas hasta la sierra de Marvão ${ }^{59}$. Por todo ello, no es descabellado pensar que la donación de Flámula y, con ella, la expansión patrimonial del monasterio hacia estos territorios tuvo más que ver con una decisión racional de la donante, basada en sus relaciones personales, que en una política de expansión del cenobio hacia esta región concreta.

53 Martín Viso, Ińaki. "Comunidades locales, lugares centrales y espacios funerarios en la Extremadura del Duero altomedieval: las necrópolis de tumbas excavadas en la roca alineadas». Anuario de Estudios Medievales, 2016, pp. 859-898, p. 878.

54 Véanse tabla 2 y figura 3.

55 PMH, DC, doc. 81 .

56 «Flamula deuota filia Ruderici et Leodegundie» (PMH, DC, doc. 81).

57 Mattoso, José. A nobreza medieval portuguesa. A familia e o poder. Lisboa: Editorial Estampa, 1981, pp. 137 y 153.

${ }_{58}$ Podemos observar una primera referencia a esta relación familiar en el testamento de la condesa Oneca, en el que aparecen, como hijas de la testamentaria, Mumadona y Leodegundia. $P M H, D C$, doc. 34

59 Mattoso, História de Portugal, p. 404. 
CASTILLOS, CASTROS Y FORTALEZAS DURANTE LA EXPANSIÓN DEL REINO DE LEÓN. PODER Y FUNCIONES EN LA MONTAÑA LEONESA Y EL INTERFLUVIO TÁVORA-CÔA (SIGLOS X-XI)

\begin{tabular}{|l|l|l|}
\hline \multicolumn{1}{|c|}{ Nombre } & Otras terminologías en la documentación & \multicolumn{1}{c|}{ Término municipal actual } \\
\hline Trancoso & Castello Trancoso & Trancoso \\
\hline Moraira & Castello Moraira & Moreira de Rei \\
\hline Longroiva & Castello Longobria & Longroiva, Mêda \\
\hline Numão & Castello Nauman & Numão-Vila Nova de Foz Côa \\
\hline Vacinata & Castello Vacinata & Muxagata \\
\hline Pena de Dono & Castello Pena de Dono & Uniáo das Freguesias de Penedono y Granja \\
\hline Alcobria & Castello Alcobria & Ranhados \\
\hline Seniorzeli & Castello Seniorzelli & $\begin{array}{l}\text { Semancelhe, Uniáo das Freguesias de } \\
\text { Semancelhe y Sarzeda }\end{array}$ \\
\hline Caria & Castello Caria & Moimenta da Beira \\
\hline Amindula & Castello Amindula & $\begin{array}{l}\text { Mêda, Uniáo das Freguesias de Mêda, Outeiro } \\
\text { de Gatos y Fonte }\end{array}$ \\
\hline Terrenio & Castello Terrenio & Terrenho, conc. de Trancoso \\
\hline
\end{tabular}

TABla 2. Castillos del interfluvio Távora-Côa adscritos al monasterio de Guimarães entre los siglos X-XI (elaboración propia a partir de BARROCA, «Fortificaçoes e povoamento»).

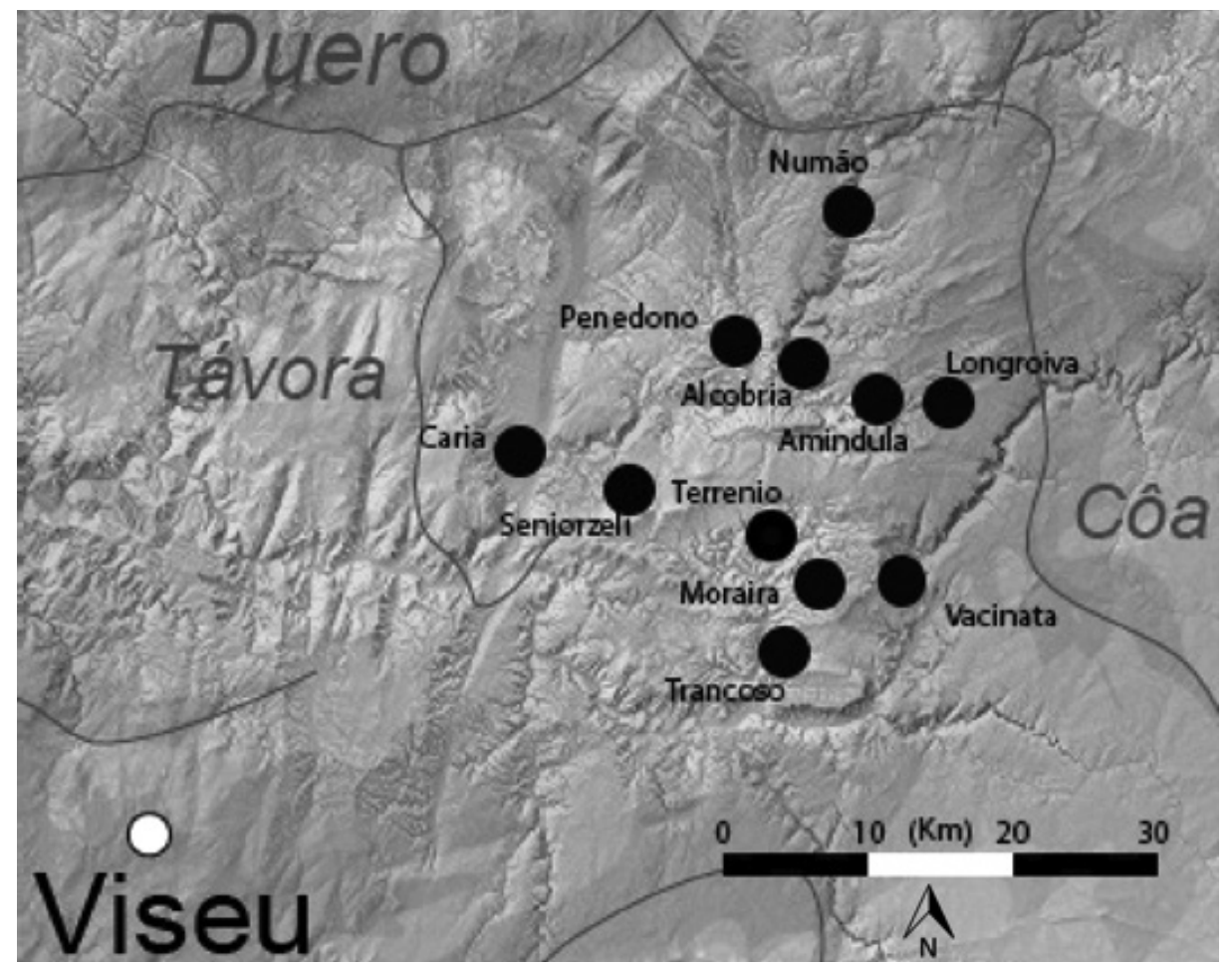

Figura 3. Mapa del interfluvio Távora-Côa con la representación espacial de los castillos identificados en la Tabla 2 (elaboración propia). 
CASTILLOS, CASTROS Y FORTALEZAS DURANTE LA EXPANSIÓN DEL REINO DE LEÓN. PODER Y FUNCIONES EN LA MONTAÑA LEONESA Y EL INTERFLUVIO TÁVORA-CÔA (SIGLOS X-XI) DANIEL JUSTO SÁNCHEZ

El análisis funcional de los castillos mencionados debe iniciarse valorando el posible reflejo de una estructura territorial jerárquica a partir de la mención a «nostros castellos [...] cum alias penellas et populaturas». Barroca defendió esta jerarquización ${ }^{60}$, situando a los castillos individualizados en la documentación en una escala superior a las penellas, estructuras castrales de funciones todavía poco definidas, que quiso hacer corresponder con distintos castelos roqueiros, fortificaciones de menor importancia erigidas en una posición dominante sobre el paisaje circundante por iniciativa de las comunidades, en lo que sería un proceso de afirmación del poder local ${ }^{61}$. Por último, las populaturas se corresponderían con unidades de poblamiento agrupado, sin defensas ${ }^{62}$. En esta estructura territorial la autoridad última correspondería al magnate, o al menos eso quiere manifestar la expresión «nostros castellos». La fórmula cuadra perfectamente con las interpretaciones de Barroca que defienden la personalización de los destinos militares de un territorio, es decir, la delegación de la iniciativa constructiva a los condes ${ }^{63}$. Aunque de nuevo nos encontraríamos, en teoría, con la delegación de un poder regio controlador del territorio hacia unos condes, en estos territorios de frontera la posesión de los castillos, al menos si tomamos las palabras de Flámula como ejemplo representativo, quedaría en manos de los magnates.

La pregunta es si estos castillos donados por Flámula en 960 se podrían identificar directamente como islas de autoridad del poder asturleonés o, por otro lado, correspondían a nódulos principales de una estructura territorial previa. Ciertamente, el documento carece de mención alguna a centros de mayor envergadura como podría ser Viseu, civitas relativamente cercana. Si nos fijamos en otras referencias a espacios de poder delegados a lo largo del reino, encontramos con frecuencia la referencia a un espacio fortificado y unos territorios -o derechos- dependientes (mediante fórmulas como quom mandationibus suis). Sin embargo, en este caso vemos la mención únicamente a alias penellas et populaturas. Por lo tanto, no podemos afirmar que del documento de donación de Flámula sea posible extraer una dependencia de penellas y populaturas respecto a los castillos. La importancia y, seguramente, el número de los tres tipos de asentamientos era desigual, hasta tal punto que uno de ellos, el castillo, era considerado lo suficientemente importante para ser mencionado de forma individualizada y nominal. Al mismo tiempo, si mantenemos las teorías de Barroca respecto a las penellas, estas deberían corresponderse con un segundo tipo de estructura fortificada, lo que lleva a pensar que la relevancia del castillo como núcleo destacado se produce a diferentes escalas.

La familia amplia de Flámula habría tenido continuas relaciones con el poder monárquico asentado en León ${ }^{64}$, por lo que la teoría del control de estos castillos por delegación

60 Barroca, «Fortificaçoes e povoamento», pp. 190-191.

${ }_{61}$ Investigaciones más recientes han identificado algunos de estos emplazamientos con lugares concretos como São Gens, Penedo dos Mouros o Quiriz. Véanse, Tente, «Viver em autarcia» y MarTín VIso, «Comunidades locales, lugares centrales».

62 Aparte de estos tres elementos estarían las casas, unidades individuales de poblamiento que no habrían sido referidas por Flámula; BARROCA, «Fortificaçoes e povoamento», pp. 190-191.

63 Barroca, «Do castelo da Reconquista al castelo románico», pp. 92-99.

64 Un ejemplo lo tenemos en las donaciones de Ramiro II a la propia Mumadona y a la iglesia de San Salvador de Guimarães, $P M H, D C$, doc. 36. 
CASTILLOS, CASTROS Y FORTALEZAS DURANTE LA EXPANSIÓN DEL REINO DE LEÓN. PODER Y FUNCIONES EN LA MONTAÑA LEONESA Y EL INTERFLUVIO TÁVORA-CÔA (SIGLOS X-XI) DANIEL JUSTO SÁNCHEZ

regia parece bastante sólida. En consecuencia, la relación del poder magnaticio, cuanto menos, con los castillos más relevantes mencionados en la donación de Flámula parece innegable. Todo ello sin negar la idea de una jerarquía territorial anterior que, a la hora de ser procesada por el nuevo poder regio, combinó espacios donde la autoridad patrimonial se ve claramente definida con otros donde es básicamente nominal. Desafortunadamente, en la documentación latina no encontramos más información sobre el particular durante el siglo $\mathrm{x}$, nada que nos hable de las acciones que se desarrollaron con posterioridad a la entrada del monasterio de Guimarães en esta zona ni de la situación anterior a la donación de Flámula. No obstante, es posible rastrear parte de esta información en algunas fuentes árabes, aprovechando la situación geográfica de los espacios de la Beira Interior y su aparición en las crónicas andalusíes.

Es posible advertir que la situación de la Beira Interior como escenario de razias y zona de paso para mayores ejércitos que se dirigían a fortalezas más eminentes o regiones más ricas fue anterior a la integración en el marco de dominio leonés. Durante algunas campañas, como la del emir Abderramán II en 838 contra Galicia, las tropas andalusíes penetraban por los pasos occidentales y depredaban las regiones de la Beira Interior, en este caso concreto, llegando a Viseu ${ }^{65}$. Llama la atención el diferente tratamiento que, durante el siglo viII, se da a las regiones cristianas desde el poder andalusí. Mientras que, al referirse a campañas contra Castilla o Galicia, los cronistas suelen remarcar la visión de estos espacios como territorio enemigo, cuando las campańas se dirigen a los espacios más occidentales situados al sur del valle del Duero, nunca se subraya esta condición de enemistad. Este fenómeno puede marcarse como un indicador de que el poder andalusí no identificaba los espacios del sur del valle del Duero con los reinos septentrionales.

En agosto de 936 encontramos la primera mención a uno de los castillos del interfluvio Távora-Côa: Trancoso. El ya califa Abderramán III ordenó una campaña contra el castillo, lo que dice hacer en respuesta a la ruptura de la paz por Ramiro II. Al mismo tiempo, se habría producido una gran victoria musulmana contra las fuerzas comandadas por Ramiro González. El texto de la crónica, traducido, nos lo cuenta en los términos que siguen:

«El jueves, 4 de sawwal de este ańo (25/08/936), tuvo lugar la tremenda victoria de los Banu Razin, Banu Din-Nun y tagarinos adheridos contra el enemigo infiel de la zona fronteriza, al que Dios derrotó tras dura batalla que les fue adversa, hasta ser casi exterminados, siendo muerto su jefe, el conde Ramiro, conocido por el hijo de Mamma Tuta [...].

Por su parte, el visir Yahya b. Ishaq, salió el jueves, 4 de sawwal de este ańo (25/08/936), de Badajoz, en algara contra los leoneses de occidente, a quienes Dios destruya, conquistando las fortalezas de .rb.gueira ${ }^{66}$ y Trancosa en la primera decena del mes, donde mató a los combatientes, se llevó cautivos a los demás y, quemando una de ellas, volvió a salvo y con botín ${ }^{67}$.

65 Cron. Emires, 179v, p. 292.

66 Topónimo no identificado con claridad, aunque comúnmente relacionado con el topónimo Ortigueira.

${ }_{67}$ Cron. AbdIII, 258, p. 285.

(C) Ediciones Universidad de Salamanca

Stud. hist., H. ${ }^{\mathrm{a}}$ mediev., 36(1), 2018, pp. 31-56 
CASTILLOS, CASTROS Y FORTALEZAS DURANTE LA EXPANSIÓN DEL REINO DE LEÓN. PODER Y FUNCIONES EN LA MONTAÑA LEONESA Y EL INTERFLUVIO TÁVORA-CÔA (SIGLOS X-XI) DANIEL JUSTO SÁNCHEZ

Podemos observar cómo la forma de referirse a los territorios fronterizos de la Marca Inferior había cambiado para el siglo x. Ya encontramos una identificación clara de estos espacios con el enemigo leonés, de hecho, el casus belli habría sido la ruptura de un acuerdo de paz por parte de Ramiro II. Al mismo tiempo, el comandante de las fuerzas cristianas era miembro de una familia condal.

Más adelante, Trancoso sería conquistada durante la decimoquinta campaña de Almanzor, entre octubre y noviembre de $981^{68}$, cuando, en virtud de lo expuesto en la donación de Flámula, ya se hallaba entre las posesiones del monasterio de Guimarães. Los demás castillos del interfluvio Távora-Côa posiblemente pasaron al poder andalusí también durante el periodo $990-997^{69}$. La conquista no supondría necesariamente un cambio de manos en la administración de los castillos, más bien la zona volvió a funcionar como una suerte de territorio tapón con poderes autónomos. En esta línea, AlKardabus nos informa de que Almanzor, en su lecho de muerte, se arrepentía de no haber desolado los territorios conquistados, dejando entrever cierta autonomía administrativa de las tierras entre al-Ándalus y los reinos cristianos ${ }^{70}$.

Independientemente de la adscripción política de la región, conviene apuntar que el único de los castillos que coincide entre el documento de donación de 960 y las crónicas musulmanas es Trancoso, lo que podría admitirse como una muestra de su papel como isla de autoridad, en relación con la autoridad asturleonesa. Llegamos en este punto a un verdadero dilema que parece irresoluble a partir del registro escrito. Trancoso aparece como un centro de particular relevancia en las fuentes de finales del siglo x, pero ¿era el único centro de esa importancia?; ¿qué lugar ocupan los demás castillos donados por Flámula en 960 y la estructura territorial jerárquica que se insinúa en dicha donación? En nuestra opinión los castillos del interfluvio Távora-Côa se encontraban en la cima de una estructura territorial engendrada con anterioridad, de la que no quedan grandes rastros documentales. Para hallar muestras de este sistema, es preciso recurrir a una serie de signos débiles que, teniendo en cuenta el papel simbólico del castillo en la sociedad, nos hablen de unos intentos de diferenciación social con raíces anteriores a los contextos bélicos en los que hemos visto mencionado Trancoso. Afortunadamente, en la Beira Interior disponemos de una manifestación material que nos puede permitir avanzar en la comprobación de nuestras hipótesis: las necrópolis de tumbas excavadas en la roca alineadas. Estas son sepulturas muy frecuentes en los terrenos paleozoicos predominantes en este sector, elaboradas directamente en la roca (normalmente granito o pizarra), $y$, en conjunto, configuran áreas funerarias altomedievales ${ }^{71}$. Debemos ser cuidadosos al analizar este tipo de restos materiales, dado que la investigación arqueológica en la región de la Beira Interior para el periodo altomedieval se encuentra todavía en una fase temprana

68 Dikr, p. 231

69 Barroca, Mario Jorge. «De Miranda do Douro ao Sabugal: arquitectura militar e testemunhos arqueológicos medievais num espaço de fronteira». Portugalia. Nova Série, 2008-2009, vol. XXIXXXX, pp. 193-252, p. 215, precisa más al afirmar que el conjunto de los castillos donados por Flámula debió caer en manos amiríes en la campaña de 997.

70 Al-Kardabus, pp. 85-87.

71 Martín Viso, «Comunidades locales, lugares centrales». 
CASTILLOS, CASTROS Y FORTALEZAS DURANTE LA EXPANSIÓN DEL REINO DE LEÓN. PODER Y FUNCIONES EN LA MONTAÑA LEONESA Y EL INTERFLUVIO TÁVORA-CÔA (SIGLOS X-XI)

DANIEL JUSTO SÁNCHEZ

de desarrollo. La mayor parte de la información hallada se ha conseguido mediante intervenciones en superficie, durante las cuales las tumbas en roca ya no solo destacan por ser el indicio mejor conservado, sino también el más evidente ${ }^{72}$. Además, su presencia en varios de estos castillos puede ser analizada como una tendencia. En este punto, resulta interesante la reciente tesis de Martín Viso, quien además de advertir de las dificultades interpretativas que entrañan las necrópolis, sugiere la posibilidad de que puedan relacionarse con las comunidades locales asentadas en los lugares centrales, reconocidas como comunidades políticas con una identidad propia, creada con anterioridad a su condición de islas de autoridad.

Tomando todo lo expuesto en consideración, los procesos que se desarrollaron en el interfluvio Távora-Côa entre los siglos X-XI, aunque todavía de difícil explicación sólida, pueden ser mejor analizados a partir de las noticias recogidas para sus lugares centrales fortificados. A partir de algunos datos de las crónicas árabes, podemos concluir que con anterioridad a las conquistas de Alfonso III, entre finales del siglo Ix e inicios del x, existía un territorio habitado y ajeno a la autoridad asturleonesa en la Beira Interior. La llegada de los conquistadores del norte, por lo tanto, se habría producido sobre unos espacios que ya se encontraban ocupados por comunidades organizadas y dotadas de una identidad propia. La relación entre necrópolis de tumbas excavadas en la roca alineadas y algunos lugares centrales puede servirnos para marcar esa identidad anterior a la llegada del poder asturleonés y, por lo tanto, nos hablaría de esa interacción entre los recién llegados y las comunidades locales. Así, el proceso de integración de estos territorios en la estructura territorial asturleonesa debió contar con la realidad que presentaba la propia región: una territorialidad surgida desde las propias comunidades locales, que habrían construido lugares centrales fortificados desde los cuales controlar los terrenos de pasto, vigilar las vías de comunicación y defender a personas y ganado frente a las acciones violentas que pudieran producirse entre las propias comunidades pero, sobre todo, frente a las incursiones propias de un territorio de frontera sin autoridad superior reconocida. Una estructura territorial que, sin embargo, plantea todavía el problema de una jerarquización poco clara, una dificultad que, tarde o temprano, la mayor intervención arqueológica podrá contribuir a resolver ${ }^{73}$.

De estos complejos procesos de integración territorial surgirían, desde aproximadamente el segundo tercio del siglo $\mathrm{x}$, unos poderes bastante autónomos respecto a la autoridad reinante en León. Esta situación sería resultado de una integración tan solo posible a través de la constitución de una serie de lugares centrales, donde la autoridad superior se percibiera, rodeados de espacios donde la estructura territorial anterior siguiera muy presente. Durante este proceso se elevaron estructuras como la torre mozárabe de Trancoso, símbolo de una autoridad superior que, en la práctica de la vida dentro de estas comunidades de frontera, no era mucho más que una

72 Martín Viso, «Comunidades locales, lugares centrales».

73 Tal y como vimos para el caso de la montańa leonesa, en la documentación de Portugal, especialmente a partir del siglo XI, es frecuente el empleo de los términos sub, subtus y ad radicem en relación con las estructuras castrales. El análisis de este tipo de noticias requiere prácticas de investigación extensivas, dada la poca información que aportan de manera aislada. 
CASTILLOS, CASTROS Y FORTALEZAS DURANTE LA EXPANSIÓN DEL REINO DE LEÓN. PODER Y FUNCIONES EN LA MONTAÑA LEONESA Y EL INTERFLUVIO TÁVORA-CÔA (SIGLOS X-XI) DANIEL JUSTO SÁNCHEZ

entelequia ${ }^{74}$. Una situación que la coyuntura y el paso del tiempo no parecen revertir por completo, aunque sí modificarla. Al menos si atendemos al documento que aporta el testimonio de la vuelta de los castillos donados en 960 por Flámula al patrimonio del monasterio de Guimarães, su inventario de 1059:

«Et in extremis ex alia parte Durio castellos. Id sunt Trancoso cum suas uillas. Longobria. Terrenio. Moraria. Naumam. Vacinata. Pennadedomno. Amendula. Seniorzelli. Alcobria et Caria. Istas penas cum toto suo deuido ${ }^{75}$.

Dado que sabemos por la Chronica Gothorum ${ }^{76}$ y el Chronicon Conimbricense ${ }^{77}$ que la Beira Interior fue recuperada por las fuerzas cristianas comandadas por Fernando I entre 1057 y 1064, podemos establecer que la devolución de los castillos al cenobio fue inmediata. La mención a penellas y populaturas había desaparecido, sustituida por una expresión, istas penas cum toto suo deuido, que evidencia el papel de los castillos como espacios centrales en torno a los que se desplegaba una jerarquía de dependencia. Asimismo, la nómina había sido aumentada a once con la inclusión de Terrenio (Terrenho, conc. de Trancoso), posiblemente uno de los espacios que engrosaban el grupo de las penellas en 960, que había ganado en importancia durante el oscuro periodo de 960-1059. Desgraciadamente, al no disponer del documento de donación de Fernando I, no sabemos si esta se produjo en unos términos que reservaran la autoridad última del monarca. Sin embargo, la forma en la que se mencionan los castillos en el inventario del monasterio, sin el empleo de la fórmula nostros castellos, nos permite establecer la conclusión, no sin reservas, de que algo había cambiado con la nueva llegada del poder septentrional al sur del Duero. El rey había sido un actor político completamente invisible de la política del interfluvio Távora-Côa en el siglo $\mathrm{x}$, en beneficio de una enorme autonomía por parte de sus delegados y de las élites locales. La donación de estos castillos de nuevo al monasterio de Guimarães estaba reconociendo la autoridad que antaño fuera ejercida sobre estos espacios, si bien queda todavía mucho por saber sobre las relaciones de poder en esta nueva situación.

3 Conclusiones: los Castillos, una vía de anÁlisis para las Sociedades del noroeste de la Península Ibérica en la Alta Edad Media

Los estudios que abordan la relación del centro fortificado con los sujetos sociales y los territorios circundantes apenas han trabajado junto a aquellos que analizan el castillo desde la perspectiva de la simbología del poder. No obstante, ambos marcos teórico-metodológicos se muestran susceptibles de aplicación al noroeste de la Península Ibérica, donde la investigación sobre los castillos en esta línea aún permanece

74 De similares características arquitectónicas que la torre de Covarrubias (Burgos), constituye el único resto pleno de fortificación que se puede fechar en el periodo estudiado. BARROCA, «Fortificaçoes e povoamento".

75 PMH, DC, doc. 420.

76 PMH, Script., pp. 9-10.

77 PMH, Script., p. 2. 
CASTILLOS, CASTROS Y FORTALEZAS DURANTE LA EXPANSIÓN DEL REINO DE LEÓN. PODER Y FUNCIONES EN LA MONTAÑA LEONESA Y EL INTERFLUVIO TÁVORA-CÔA (SIGLOS X-XI)

en gran medida por hacer. Este tipo de investigaciones se insertan en un momento historiográfico en el que el estudio de la Alta Edad Media y, más concretamente, del periodo entre los siglos IX al XI, cada vez se aleja más de la visión casi teleológica que identificaba al feudalismo como el exclusivo concepto explicativo del momento. De hacerlo, estaremos cometiendo el gravísimo error de menospreciar los propios mecanismos de funcionamiento de las estructuras políticas, sociales y económicas de la época altomedieval. Las funciones y el control de los castillos, así como el dominio territorial ejercido desde ellos, se insertaban como una parte importante dentro del juego de poderes; si bien no constituían la única manifestación del poder. La admisión de esta premisa permite plantear que la afirmación del poder de ciertos actores políticos se pudiera canalizar a través de los propios castillos. Este fenómeno, muy evidente en el incastellamento, constituía tan solo una posibilidad dentro del amplio abanico de alternativas que los actores políticos manejaban en los juegos de poder. Independientemente de que no sea posible relacionar el noroeste de la Península Ibérica con procesos de incastellamento, la eminencia que los castillos podían tener en el propio paisaje, la simbología del poder de sus propias estructuras y su relación con el territorio circundante, hacen que el estudio de las funciones de los castillos en el periodo sea de una gran importancia para conocer unos juegos de poder que, hoy en día, tienen todavía mucho que contar ${ }^{78}$. Una conclusión en esta línea versa sobre cómo la función y la importancia de cada uno de los castillos variaba según las zonas.

Concretamente, el análisis de los castillos de las dos regiones escogidas nos ha permitido extraer algunas conclusiones que ponen de manifiesto la complejidad de un Reino de León que dista mucho de la uniformidad apreciable únicamente mediante una visión desde arriba y de manera muy superficial. A pesar de que tanto la montańa leonesa como el interfluvio Távora-Côa se encontraban durante el siglo x bajo la autoridad del monarca regnante in Legione, el dominio de este no se apreciaba con igual intensidad en ambas regiones, ni el poder se encauzaba de la misma forma. Mientras que en la montaña leonesa la influencia de los monarcas se manifiesta de manera muy clara ya a finales del siglo Ix, en el interfluvio Távora-Côa no llegamos a percibir una actuación similar en ningún momento del periodo estudiado ${ }^{79}$. Es posible que la diferente realidad de las dos regiones fuera el resultado de la combinación de la existencia de distintas estructuras territoriales preexistentes y de dispares procesos de integración. Hemos visto cómo, para mediados del siglo x, cuando Flámula dona sus castillos del interfluvio Távora-Côa la región presentaba una estructura territorial dentro de la cual, aunque no sea identificable una clara jerarquía, castillos, penellas y populaturas debían ocupar un lugar determinado.

78 No podemos olvidar que incluso la propia mención, o no, de un castillo en la documentación fue el resultado de un juego de poderes en el que participaban aristócratas, monarcas, instituciones eclesiásticas y élites locales; no surgieron de decisiones aisladas tomadas por un poder central. CARVAJAL CAstro, "Castra and castella» [en prensa].

79 De hecho, la única muestra de presencia directa del monarca en la Beira Interior la tendríamos en el breve periodo en que Ramiro II se asentó en Viseu. Un episodio a partir del cual no es posible afirmar el reforzamiento de la autoridad del monarca sobre los castillos del interfluvio Távora-Côa, puesto que este nos obligaría a admitir la agencia de Viseu sobre la zona, un fenómeno que no se halla sustentado en las fuentes. 
CASTILLOS, CASTROS Y FORTALEZAS DURANTE LA EXPANSIÓN DEL REINO DE LEÓN. PODER Y FUNCIONES EN LA MONTAÑA LEONESA Y EL INTERFLUVIO TÁVORA-CÔA (SIGLOS X-XI) DANIEL JUSTO SÁNCHEZ

Esta situación se relaciona con una prácticamente inexistente agencia del monarca, que deja en manos de los magnates incluso la posesión de los castillos. Al mismo tiempo, se aprecia una mayor autonomía de las comunidades y élites locales, dotadas de identidad propia. A modo de contraste, en la región montañosa de León la acción del monarca, canalizada a través de sus delegados, se encuentra mucho más presente, al mantener este la autoridad última sobre cada uno de sus castillos. Este mecanismo del juego de poderes nos ha permitido lanzar la hipótesis de que, así como los magnates ejercían funciones delegadas del poder regio en los castillos de mayor eminencia territorial, las élites locales se habrían podido aprovechar de estrategias similares para aumentar su estatus, integrándose como delegados del monarca y magnates en otros espacios fortificados de menor eminencia.

La principal conclusión comparativa que nos es posible extraer del estudio es, por lo tanto, la diferente intensidad con la que la figura del monarca está presente en las dos regiones estudiadas. Podemos afirmar que la monarquía participa en la montańa leonesa como un actor político directo, reservándose un vivero de autoridad amplio y efectivo, mientras que en el interfluvio Távora-Côa su presencia tan solo puede apreciarse indirectamente, a través de la relación existente con los magnates que sí actúan directamente en la zona. Al mismo tiempo, los escasos momentos en los que la acción regia es claramente apreciable en el interfluvio Távora-Côa, muestran que su autoridad toma más forma de discurso político que de acción efectiva. Este fenómeno se aprecia muy bien en la devolución efectuada por Fernando I en favor del monasterio de Guimarães de los castillos donados en su día por Flámula al cenobio. Un evento que, como dijimos, puede ser interpretado, principalmente, como un reconocimiento de la autonomía de los poderes ejercidos en esos espacios. Sin embargo, parece que la situación, mediante la intervención directa del monarca en la región, estaba sufriendo una cierta mutación cuyas consecuencias sería interesante observar en tiempos posteriores.

Si buscáramos una explicación sencilla para esta dispar situación, la característica del territorio portugués como frontera podría ser identificada como el factor determinante. Sin embargo, aunque admitimos que, evidentemente, este es un factor para tener muy en cuenta, no suscribimos en su totalidad un argumento que, de nuevo, redundaría en una simplificación del espacio noroccidental de la Península a una dicotomía retaguardia-frontera. Estos planteamientos desprecian los procesos de desarrollo autónomo de cada una de las zonas, que no por estar más silenciados en las fuentes carecen de interés. De este modo, consideramos que es necesario elaborar un estudio en profundidad para más espacios del noroeste peninsular, sobre todo con el fin de encontrar signos débiles capaces de proporcionarnos, a través del estudio de los castillos, un mejor conocimiento de las sociedades que allí habitaban. Una correcta combinación de las metodologías que estudian la relación territorial de los castillos, con aquellas que analizan la simbología del poder, puede ser beneficiosa para este fin. A modo de cierre, es preciso señalar que una mayor intervención arqueológica en los castillos, pero también en sus espacios circundantes, sería muy beneficiosa para identificar estos signos débiles, sobre todo aquellos que muestran momentos de jerarquización social de los espacios. Siendo conscientes de la dificultad de la tarea, consideramos que es 
CASTILLOS, CASTROS Y FORTALEZAS DURANTE LA EXPANSIÓN DEL REINO DE LEÓN. PODER Y FUNCIONES EN LA MONTAÑA LEONESA Y EL INTERFLUVIO TÁVORA-CÔA (SIGLOS X-XI)

DANIEL JUSTO SÁNCHEZ

pertinente realizar un vaciado de la documentación existente, que englobe una mayor amplitud geográfica y cronológica, con el fin de conocer mejor qué papel jugaron los castillos en los importantes procesos históricos del periodo.

\section{ReFERENCIAS BIBLIOGRÁFICAS}

Afonso Vieira, Marina. «Reflexóes em torno do povoamento alto medieval da bacia superior do rio Paiva». En MARTín VIso, Ińaki (ed.). ¿Tiempos oscuros? Territorios y sociedad en el centro de la Peninsula Ibérica (siglos VII-X). Madrid: Sílex, 2009, pp. 93-105.

Barroca, Mario Jorge. «Do castelo da Reconquista al castelo românico (Séc. IX a XII)». Portugalia. Nova Série, 1990-1991, vol. XI-XII, pp. 89-134.

BARROCA, Mario Jorge. «Aspectos da evoluçâo da arquitectura militar da Beira Interior». En Beira Interior: história e patrimonio. Actas das I Jornadas de Património da Beira Interior, 1-3 de Octubro de 1998. Guarda: Aprova, 2000, pp. 215-238.

Barroca, Mario Jorge. «Fortificaçoes e povoamento no Norte de Portugal (Séc. IX a XI)». Portugalia. Nova Série, 2004, vol. XXV, pp. 181-203.

BarroCA, Mario Jorge. «De Miranda do Douro ao Sabugal: arquitectura militar e testemunhos arqueológicos medievais num espaço de fronteira». Portugalia. Nova Série, 2008-2009, vol. XXIX-XXX, pp. 193-252.

Carvajal CaSTRo, Alvaro. «Sociedad y territorio en el norte de León: Valdoré, los Flaínez y el entorno del alto Esla (siglos IX-XI)». Studia Historica. Historia Medieval, 2013, vol. 31, pp. 105-131.

Carvajal CASTRo, Álvaro. «Los castros de la meseta del Duero y la construcción de la monarquía asturleonesa: el caso de Melgar en el siglo X». En Paisagens e poderes no Medievo Ibérico: actas do Encontro Ibérico de Jovens Investigadores em Estudos Medievais-Arqueologia, História e Património. Braga: Centro de Investigação Transdisciplinar «Cultura, Espaço e Memória» da Universidade do Minho, 2014, pp. 11-29.

Carvajal CAstro, Álvaro. «Castra and castella as symbols of power and authority in early Medieval León $\left(9^{\text {th }}-11^{\text {th }}\right.$ c.)川 [en prensa].

Cousson, Charles L. H. «Structural symbolism in Medieval Castle architecture». Journal of the British Archaeological Association, 1979, vol. 132, pp. 73-90.

Coulson, Charles L. H. Castles in medieval society: fortresses in England, France, and Ireland in the Central Middle Ages. Oxford-New York: Oxford University Press, 2003.

Creighton, Oliver H. Castles and landscapes: power, community and fortification in medieval England. London: Oakville, 2002.

Creighton, Oliver H. Early European castles: aristocracy and authority, AD 800-1200. London: Bloomsbury, 2012.

DaviES, Wendy. «Settling disputes in early medieval Spain and Portugal: a contrast with Wales and Brittany?». En Griffiths, Ralph Alan y Schofield, Phillipp R. (eds.). Wales and the Welsh in the Middle Ages. Cardiff: University of Wales, 2011, pp. 89-107.

Debord, André. Aristocratie et pouvoir. Le rôle du château dans la France médiévale. Paris: Picard, 2000.

Fernández Flórez, José Antonio y Herrero de la Fuente, Marta. Colección documental del monasterio de Santa María de Otero de las Dueñas. Vol. I (854-1108). León: Centro de Estudios e Investigación San Isidoro, 1999.

Floriano Cumbreño, Antonio C. Diplomática española del período astur: estudio de las fuentes documentales del Reino de Asturias. 3 vols. Oviedo: Instituto de Estudios Asturianos, 1949-1951. 
CASTILLOS, CASTROS Y FORTALEZAS DURANTE LA EXPANSIÓN DEL REINO DE LEÓN. PODER Y FUNCIONES EN LA MONTAÑA LEONESA Y EL INTERFLUVIO TÁVORA-CÔA (SIGLOS X-XI) DANIEL JUSTO SÁNCHEZ

Fournier, Gabriel. Le château dans la France médiévale. Essai de sociologie monumentale. Paris: Aubier Montaigne, 1978.

Francovich, Ricardo. "L'incastellamento e prima dell'incastellamento». En Barceló, Miquel y Toubert, Pierre (dirs.). L'incastellamento: actas de las reuniones de Girona, 26-27 noviembre 1992, y de Roma, 5-7 mayo 1994. Roma: École Française de Rome-Escuela Española de Historia y Arqueología en Roma, 1998, pp. 13-20.

Francovich, Ricardo y Hodges, Richard. Villa to village: the transformation of the Roman countryside. London: Bloomsbury, 2003.

García de Cortázar, José Ángel. La sociedad rural en la España medieval. Madrid: Siglo XXI, 1988.

Gil Fernández, Juan; Moralejo, José Luis y Ruiz de la Peña Solar, Juan Ignacio. Crónicas asturianas. Oviedo: Universidad de Oviedo, 1985.

Gutiérrez GonzÁlez, José Avelino. Fortificaciones y feudalismo en el origen y formación del reino leonés (siglos IX-XIII). Valladolid: Universidad de Valladolid, 1995.

Gutiérrez GonZÁLez, José Avelino. «La fortificación pre-feudal en el norte peninsular. Castros y recintos campesinos en la Alta Edad Media». En Mil Anos de Fortificaçoes na Península Ibérica e no Magreb (500-1500). Simpósio Internacional sobre Castelos. Lisboa: Ediçóes Colibrí, 2002, pp. 19-28.

Gutiérrez GonZÁLEz, José Avelino. «La implantación feudal y las fortificaciones en los orígenes del Reino de León». En Huerta Huerta, Pedro Luis (coord.). Actas del IV Curso de Cultura Medieval: Seminario, la fortificación medieval en la Peninsula Ibérica: Centro de Estudios del Románico, Aguilar de Campoo, 21-26 de septiembre de 1992. Aguilar de Campoo: Fundación Santa María La Real, 2001, pp. 81-102.

Gutiérrez González, José Avelino. Peñaferruz (Gijón). El castillo de Curiel y su territorio. Gijón: VTP Editorial, 2003.

Hodges, Richard. Light in the Dark Ages: The rise and fall of San Vincenzo al Volturno. London: Cornell University Press, 1997.

Ibn Al-Kardabus. Historia de Al-Andalus (traducción y notas de Felipe Maíllo Salgado). Madrid: Akal, 2008.

Iвn Hayyan. Crónica de los emires Alhakam I y Abdarrahman II entre los años 796 y 847 [Almuqtabis II-1] (traducción y edición de Mahmud Ali Makki y Federico Corriente). Zaragoza: Universidad de Zaragoza, 2001.

Johnson, Matthew. Behind the castle gate: from Medieval to Renaissance. London: Routledge, 2002. King, David J. C. Castellarium Anglicanum. New York: International Publications, 1983.

Liddiard, Robert. Castles in context. Power, symbolism and landscape. 1066 to 1500. Macclesfield: Windgather Press, 2005.

Marazzi, Federico; Potter, Tim W. y King, Anthony. «Mola di Monte Gelato (Mazzano Romano - VT): notizie preliminari sulle campagne di scavo 1986-1988 e considerazioni sulle origini dell'incastellamento in Etruria Meridionale alla luce di nuovi dati archeologici». Archeologia Medievale, 1989, vol. 16, pp. 103-120.

Martín VISO, Iñaki. «Comunidades locales, lugares centrales y espacios funerarios en la Extremadura del Duero altomedieval: las necrópolis de tumbas excavadas en la roca alineadas». Anuario de Estudios Medievales, 2016, pp. 859-898.

Martín Viso, Ińaki. «Riflessioni sull'incastellamento nella Penisola Iberica: la Castiglia dell'Ebro e la transierra di Madrid». Archeologia Medievale, 2001, vol. 28, pp. 83-107.

Martín Viso, Iñaki. Poblamiento y estructuras sociales en el norte de la Peninsula Ibérica, siglos VIXIII. Salamanca: Ediciones Universidad de Salamanca, 2000. 
CASTILLOS, CASTROS Y FORTALEZAS DURANTE LA EXPANSIÓN DEL REINO DE LEÓN. PODER Y FUNCIONES EN LA MONTAÑA LEONESA Y EL INTERFLUVIO TÁVORA-CÔA (SIGLOS X-XI)

Martínez Sopena, Pascual. La Tierra de Campos occidental: poblamiento, poder y comunidad del siglo X al XIII. Valladolid: Institución Cultural Simancas, 1985.

Matтoso, José. A nobreza medieval portuguesa. A familia e o poder. Lisboa: Editorial Estampa, 1981. Mattoso, José. História de Portugal. Antes de Portugal. Lisboa: Editorial Estampa, I 997.

Mínguez Fernández, José María. «Innovación y pervivencia en la colonización del valle del Duero». En Despoblación y colonización del Valle del Duero: siglos VIII-XX. Ávila: Fundación Sánchez-Albornoz, 1995, pp. 45-80.

Molina Martínez, Luis. "Las campañas de Almanzor a la luz de un nuevo texto". Al-Qantara, 1981, vol. 2, n. ${ }^{\circ}$ 1, pp. 210-263.

Pastor de Togneri, Reyna. «Formación y consolidación del feudalismo castellano-leonés. Siglos X-XiII». En Malpica Cuello, Antonio y Quesada Quesada, Tomás (eds.). Los orígenes del feudalismo en el mundo mediterráneo. Granada: Universidad de Granada, 1994, pp. 317-331.

Pérez de Urbel, Justo. Sampiro, su crónica y la monarquía leonesa en el siglo X. Madrid: Consejo Superior de Investigaciones Científicas, 1952.

Pérez Rodríguez, María. Jerarquización territorial y escenarios de poder en la cuenca del Duero: los valles benaventanos, los valles leoneses y el bajo Cea (siglos X-XII). Salamanca: Universidad de Salamanca, 2015 [tesis doctoral inédita].

Portugaliae monumenta historica a saeculo octavo post Christum usque ad quintumdecimum. Diplomata et chartae. Vol. I. Nendeln: Kraus Reprint, 1967 (1. a ed. 1867).

Portugaliae monumenta historica a saeculo octavo post Christum usque ad quintumdecimum. Scriptores. Vol. I. Nendeln: Klaus Reprint, 1967 (1. a ed. 1867).

Quirós Castillo, Juan Antonio. El incastellamento en el territorio de la ciudad de Lucca (Toscana): poder y territorio entre la Alta Edad Media y el siglo XII. Oxford: BAR, 1999.

Quirós Castillo, Juan Antonio. «L'eccezione che conferma la regola? Incastellamento nella valle dell'Ebro nel x secolo: il castello di Treviño». Archeologia Medievale, 2011, vol. 38, pp. 113-136.

Rodríguez DíAz, Elena E. El Libro de la Regla Colorada de la catedral de Oviedo, estudio y edición. Oviedo: Real Instituto de Estudios Asturianos, 1995.

Ruiz Asencio, José Manuel. Colección documental del archivo de la Catedral de León (775-1230). III (986-1031). León: Centro de Estudios e Investigación San Isidoro, 1987.

Ruiz Asencio, José Manuel y Ruiz Albi, Irene. Colección documental del monasterio de San Pedro de Eslonza. Vol. I (912-1300). León: Centro de Estudios e Investigación San Isidoro, 2007.

SÁez Sánchez, Emilio y Sáez Sánchez, Carlos. Colección documental del archivo de la Catedral de León (775-1230). II (935-985). León: Centro de Estudios e Investigación San Isidoro, 1987.

Tente, Catarina. «Viver em autarcia. A organizaçao do territorio do alto Mondego (Portugal) entre los séculos v a X». En Martín VIso, Iñaki (ed.). ¿Tiempos oscuros? Territorios y sociedad en el centro de la Península Ibérica (siglos VII-X). Madrid: Sílex, 2009, pp. 137-157.

Tente, Catarina. "Settlement and society in the Upper Mondego Basin (Centre of Portugal) between the $5^{\text {th }}$ and the $11^{\text {th }}$ centuries». Archeologia Medievale, 2012, vol. 39, pp. 385-398.

Toubert, Pierre. Les structures du Latium médiéval. Le Latium méridional et la Sabine du IX siècle à la fin du XII siècle. Roma: École Française de Rome, 1973.

Toubert, Pierre. Castillos, señores y campesinos en la Italia medieval. Barcelona: Crítica, 1990.

Wickham, Chris. "A che serve l'incastellamento?». En Barceló, Miquel y Toubert, Pierre (dirs.). L'incastellamento: actas de las reuniones de Girona, 26-27 noviembre 1992, y de Roma, 5-7 mayo 1994. Roma: École Française de Rome-Escuela Española de Historia y Arqueología en Roma, 1998, pp. 31-41. 